Article

\title{
The Case for Hand Stencils and Prints as Proprio-Performative
}

\author{
Patricia Dobrez \\ Independent scholar, 9 Blair Street, Watson, Australian Capital Territory, 2602, Australia; \\ E-Mail: u4045668@anu.edu.au
}

Received: 29 October 2013; in revised form: 11 November 2013 / Accepted: 12 November 2013 /

Published: 5 December 2013

\begin{abstract}
Hand stencils and prints are found globally in rock art, reflecting the sine qua non role of the hand in human evolution. The body itself is the tool, and it affords the registering, in the form of a trace, of what perceptual psychology terms an "ecological self". More than a "signature", a hand mark is uniquely "proprio-performative", combining inscription of individuality with direct address. The first part of this paper looks at what might get in the way of a universally readable primary meaning by methodically addressing issues of technique and cultural specificity. Having cleared the ground, it proceeds to make its argument for hand stencils and prints as constituting a special category of rock art imagery. It does this by having recourse to ideas currently under discussion in cognitive psychology: awareness of self-agency and body-ownership, as well as the notion of perceived looming in pictures. Finally, an appeal is made to the claim for a key mirror neuron role in communication. Because they are traces of actions eliciting mirror-neuronal responses, hand marks are seen as affording a readily accessible external term in an exchange of meaning on which a system of graphic communication might be built.
\end{abstract}

Keywords: rock art; hand stencils and hand prints; technique; cultural specificity; decorated hands; patterned hands; gestural language; looming; representational momentum; mirror neurons; proprio-performatives

\section{Introduction}

The intricate architecture of the human hand, which endows our species with manipulative dexterity outside the range of its nearest relatives, makes it our principal organ for exploring the world. In his classic 1980 text, Hands, John Napier went as far as asserting that the function of the sapiens sapiens 
hand in the cardinal act of negotiating environments gives it "advantages over the eye", for "it can see around corners and it can see in the dark". What is more, its operation from the end of manoeuvrable arms allows for directed movement at a distance from the body ([1], p. 8). The mutual reinforcement of haptic and visual information in perception is supported by the theory of J. J. Gibson (1904-1979) influential in the study of vision and related systems - who affirmed: "Many of the properties of substances are specified to both vision and active touch". Gibson argued that once we become aware of the "exploratory", as well as the more obtrusive "performatory" function of the hand, i.e., its role in seeking information as well as performing actions, it comes into focus for us as "a sense organ" ([2], p. 104, p. 123). The present paper relies on insights drawn from perceptual psychology and cognitive science about these functions, asking questions about how it is we recognize ourselves as originating an action, and what we understand about ourselves from our interactions with the world. It argues that hand stencils and prints register the hand's exploration of an affordant surface by capturing an image of the performatory act. This records the agent's ownership of that act and opens up the possibility of direct address to another person as well as offering options for symbolic forms of communication.

\section{The Hand's Evolution}

The hand's capacities have been with us since the time of our ancient antecedents. Recent evidence from 3.39 Ma bones bearing cut marks, found at Dikka, Ethiopia [3,4], suggest that australopithecines - who appear to have possessed the hands necessary to use pebble choppers to pound, chop and dig ([5], p. 455) — did in fact use such tools. However, the earliest finds of manufactured tools, from Gona, Ethiopia, date from about 2.5 million years ago [6]. When in 1960 hand bones suggesting grasping capabilities [7,8] were found at Olduvai Gorge, Tanzania, with apparently manufactured tools dated at around 1.75 million BP, a benchmark was set for investigating the relationship between primate hand morphology and possible tool use. Although "Oldowan tools" which predate Homo habilis - "Oldowan" and "habilis" both named as a consequence of the 1960 discoveries - have been found with australopithecine remains, archaeologists have not wanted to make claims for a tool-making species exhibiting smaller brain size than that of the habilines. With the appearance of Homo erectus about 1.5 million years ago came the long-lasting, more specialized Acheulian toolkit, and with Homo sapiens, especially in the last 100,000 years, tools which were even more task-specific ([9], pp. 110-115).

From the point of view of comparative primate hand morphology, the hominin hand possesses a number of special attributes. These include an opposable thumb-which apes also possess —and rotational abilities in the index and fifth fingers. Marzke and Marzke characterize the modern human hand as allowing flexibility in the thumb's opposition to the other four fingers without compromising thumb-to-index finger grips. Affecting the hand's control over an object, human thumb length is longer in relation to the index finger than for our near relatives [8], and grip is aided by ample and malleable pulp-contact at finger ends [8,10]. Humans grip more powerfully than other primates ([11], p. 108).

It was the hand as performatory which preoccupied Darwin when, with the 1871 publication of the Descent of Man, he drew attention to its critical role in determining our place in the ecosystem:

Man could not have attained his present dominant position in the world without the use of his hands, which are so admirably adapted to act in obedience to his will... But the hands and arms 
could hardly have become perfect enough to have manufactured weapons, or to have hurled stones and spears with a true aim, as long as they were habitually used for locomotion and for supporting the whole weight of the body... ([12], p. 279).

The drawing of a connection between bipedalism and the freeing of the hand for tool use is currently under intense discussion as biologists seek to throw light on the relationship between these evolutionary events, with questions asked about the "when and how" ([13], p. 1566) of the adaptive sequence. In 1964, while assessing Homo habilis fossils found at Olduvai Gorge in collaboration with (Louis) Leakey and Tobias, Napier noted both differences and resemblances when habilis hand bones were compared with those of sapiens sapiens ([7], p. 8). Since then research has focused on the evolution of hand morphology, although a scarcity of hand bone fossil evidence makes this difficult-despite improved techniques in comparative analysis [8,14]. Recent investigation has raised the question of a correlated evolution of hands and feet, with Rolian et al. [13] arguing for parallel development. Anatomical inquiry emphasizing biomechanics has led to neurophysiological investigations, with experiments by, for example, Peeters et al. [15] pointing to an evolved human brain area, which relates to causal awareness in tool use. In experiments with macaques, Gross et al. [16] accidentally triggered a specific neuronal response to a waved hand in the inferotemporal cortex (the processing area for objects). Following this, a substituted monkey or human hand shadow produced the same result. It has long been recognized that the representation of the human hand, together with that of the face, takes up a large area of the brain, as proportionally illustrated by Penfield and Rasmussen in 1950 ([17], p. 44, Figure 17).

The hand is emerging as central to the evolution of human communication, with Arbib supplying the "missing link" in the emergence of language by arguing for the recruitment of mirror neuronswhich developed in relation to grasping actions - in response to an enlarging repertoire of manual gestures [18]. Rizzolatti et al. have reviewed evidence from brain-imaging experiments in support of motor system resonance while observing an action ("the direct-matching hypothesis"), claiming a common activation location for "observed arm or hand actions" and speech, viz. Broca's area, "a region traditionally considered to be exclusively devoted to speech production". They justifiably see this as suggesting "an interesting evolutionary scenario, linking the origin of language with the comprehension of hand actions" ([19], p. 664) [20]. Arbib has proposed a proto-Broca's area possessed by Homo habilis and erectus that primed the species for language-readiness. On this neurolinguistic hypothesis, a role for vocalization recedes, and manual gesture comes to the fore as having a foundational role [18].

The capacity of the hand, either as direct instrument in the case of finger flutings, stencils and prints, or for the manipulation and manufacture of tools, is understood in rock art studies, but only a small number of rock art researchers focus on its role in cognitive evolution. Indeed the hand in all its aspects is inescapably chief protagonist in any story of rock art. Setting the scene for the advent of art, Lorblanchet links several important symbiotic factors ("une symbiose de processus") in which it is not easy to disentangle cause and effect. These are a postural shift to bipedalism, hands freed for tool-manufacture and mouth freed from merely obtaining food, increased dexterity in the employment of hands, and an altered brain ([21], p. 58). Whatever the complications of this symbiosis, the hand is to be understood as crucial to survival and integral to species definition (Figure 1). 
Figure 1. Painted hand, Madhya Pradesh.

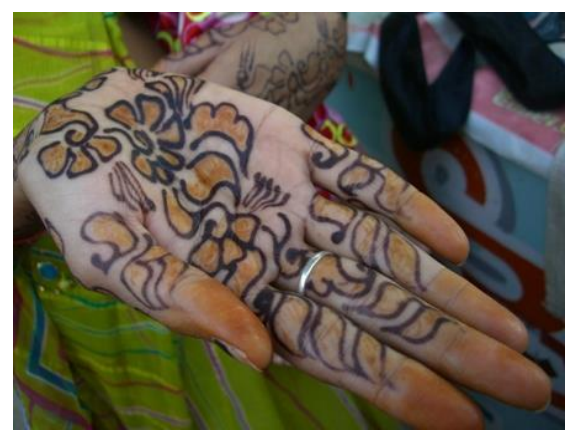

\section{The Longevity of Hand Stencil- and Print-Making}

In view of this, should it surprise us that perhaps the most tantalizing manifestation of human marking around the world, with an antiquity of its own, is the stenciling and printing of the human hand? In mid 2012 the 27,000+ BP date for Cosquer, France ([22], pp. 78-79) appeared to be overtaken by El Castillo, Spain, when Pike et al. [23] published their uranium-series calculation of at least 37.3 thousand years for a hand stencil and 40.8 for a red disc. Aware of the difficulties of this type of dating analysis, Bednarik [24] recommends caution in accepting the result. Still, the Pike et al. claim raises the possibility, supported by broader evidence of robust populations, that the images were made by Neanderthals [23]. Marzke and Shackley, describing Neanderthal hands, assert their skeletal similarity to those of modern humans, but note possession of "large muscles" ([5], p. 454). It is astonishing to think that in one instance we might be looking at the image of a Neanderthal hand and in another that of a contemporary modern who is nonetheless an inheritor of this particular rock art tradition. It is a fact that in Australia both stencils ([25], pp. 74-75; [26], p. 12) and positive prints ([27], p. 30, p. 32) have been made by Aboriginal people within living memory. There is also evidence of tribal groups in Central India continuing hand printing practices at rock art sites ([28], p. 380).

A 37.3 thousand minimum date aside, taphonomic considerations $[29,30]$ prompt us to rule out hypothesizing a time-frame for the first appearance of hand stencils and prints. Their genesis must be in the exploratory activity of the hand as it leaves a trace of itself; their antiquity as long as that of the hand which was capable of making a mark. The unanswerable question is: when did casual marks become intentional? In the present context, another question might be asked: is there a rationale for focusing on stencils and prints? After all, directly imprinted hand images, either positive or negative, have obvious affinity with other hand-made marks not involving tools. Findings at Cosquer suggest that stenciled and printed hands were contemporaneous with finger flutings ([22], p. 63). What puts them in a different category from finger flutings like those of Cosquer or (to give Australian examples) Koonalda or Karlie-ngoinpool caves, is their quasi-representational iconic character. A clear and distinct image of a hand will be recognized as a hand. Like stencils and prints, flutings retain visual testimony of how (and by whom) they were made. What gives the former a special status among early rock art forms, and one that opens out a separate line of inquiry into their defining features, is their iconicity. This cannot be said for all variations of the hand mark. For example, images of the palms of hands, such as we find at Chauvet, will not qualify as iconic. The makers of these palm-blobs may well have been identifiable by others within the group attending to the size and other characteristic features 
of the prints, but the fact that their production by pads rather than palms lends itself to creating non-hand images - for example, for producing the profile of an animal ([31], p. 157, p. 71) -means that they are very different in kind from the hand-recognized-as-hand class of image. This is also the case for the triangular "masked stencils", ancient or recent, occurring in Arnhem Land, Australia [32]. However, the category of the iconic hand will extend to hands with bent fingers, provided the aim is not to depict a quite different iconic image such as a bird or animal head. The general class of recognizable hand images will of course include painted, drawn and petroglyph representations. However, only stencils and prints have the special quality of directly replicating the hand that made them.

Accordingly, taking their iconicity as a given, but with no intention of dismissing the subject of their possible use within a language of symbols, I propose to look again at a range of matters which have concerned students of this particular category of hand images. My aim in addressing issues of technique and cultural specificity is to rule out what does not bear on my argument and to foreground what does. I shall also examine what hand stencils and prints have in common with those of the human foot. When I make my case for a special proprio-performative category for rock art hand marks, ancient and modern, I shall explain why painted, drawn or petroglyph hand images are excluded.

\section{Technique}

From Régnault's "tamponnage" application method to Breuil's tube of bone (cf. the claimed blow-pipe technique of Lascaux), the technique of making hand stencils has been a hot issue in rock art studies ([33], p. 46; [34], p. 45, p. 144) - until, that is, the majority of Anglophone researchers settled down to the view represented in IFRAO's Rock Art Glossary English definition which specifies a spraying of pigment "usually from the mouth". It is interesting that the key verb used in the French definition of "main en negative" is not the equivalent of "to spray" ("vaporiser" or "atomiser"), but "répandre" ("spread" or "diffuse") — with no mention of "la bouche" ([35], p. 16, p. 88). This seems to leave the matter undecided, with the French definition reflecting the French debate. Breuil's collaborator at Gargas, Cartailhac, proposed that dry powdered color was projected onto a moist surface, thus becoming fixed. Other methods have been canvassed: Groenen suggested the use of a vaporizer made of two small tubes at a right angle, and Lorblanchet, with the experience of working in Australia, where such a method had been recorded, mixing of saliva and pigment in the mouth prior to spitting ([36], p. 121). Barrière and Sueres, who examine all these proposals, opt for a version of the Lorblanchet suggestion [33]. Breuil had previously referred to blowing from the mouth "in the manner of the Australians" ([34], p. 45), suggesting this as an Aurignacian method. Something of this conversation about technique is surely reflected in Keyser and Klassen where stencils at Wyoming sites are said to have been made by "blowing paint through a tube or spitting it directly from the mouth" ([37], p. 7). In Santa Cruz, Argentina, Breuil lives on in the ochred tube model exhibited at the Cueva de las Manos tourist center - justified by the find during excavations of a tube, stained red and bearing signs of use ([38], p. 245) - although researchers at Cueva de Las Manos also take up the spreading/spraying from the mouth option ([39], p. 27). A bone tube carrying remnants of ochre was also found at Les Cottés, Vienne ([36], p. 119). 
From Australian ethnography, two accounts are worth mentioning. The first can possibly be sourced to the 1880s, when a boy growing up with Aborigines on the Darling River, western New South Wales, might have observed at close hand the blowing-from-the mouth method he advances half a century later. McCarthy quotes G. K. Dunbar's recollection: "women and children expressed their desire for the creation of some artistic object by filling the mouth with a mixture of kopi (white clay) and blowing it over the hand placed against a rock" ([40], p. 74). The second is Herbert Basedow's 1925 testimony of a method, which, he confidently asserts, "is met with all over the continent":

The person puts a small handful of ochre or pipe-clay into his mouth and crunches it to a pulp; then he fills his mouth with water and thoroughly mixes the contents. He holds the hand he wishes to stencil against a flat surface, spacing the fingers at equal distances, and spurts the contents of his mouth all about it. A short while after, the hand is withdrawn. The area which it covered remains in its natural condition, whilst the space surrounding it has adopted the color of the ochre or clay ([41], p. 321).

A more recent Australian account of this method being used in the Kimberley in the 1930s is cited by Mulvaney ([26], p. 17), and Tresize ([42], p. 198), familiar with Cape York practices, takes it as a given.

Common to these descriptions is the assumption that the human hand is held to the rock face to register its form. While speculation about what is a global activity suggests that it might have involved varying techniques across space or time - and must mean different things in different situations ([21], p. 218; [43], p. 98) — we can be sure that the act of leaving a recognizable trace of one's hand on a surface by direct contact is what ultimately facilitates an investment of cultural meaning. This is not a matter for dispute and provides one of the planks in my argument for a special category of rock-marking for hand stencils. I would also add prints (called "impressed hands" in some contexts [44]) to the category, since they satisfy the criteria of surface contact and the capture of idiosyncratic form through trace. Unlike the "negative imprint" (the expression employed by Basedow), the "positive" does not provoke dispute about its execution. Basedow's straightforward Australian description is unlikely to meet with opposition: "At times... the hand is smeared with ochre and smacked again [sic] a surface to obtain a positive" ([41], p. 322).

\section{Cultural Specificity}

While ethnography relating to hand stencils and prints can throw light on a range of cultural attitudes and practices, it is a level of meaning prior to cultural meaning which interests us here, viz. the one which is accessed when a hand mark is recognized as a hand fixed in the moment of its making. This prior meaning, iconic but in a way that is special, is accessed universally and is what allows an individual stencil or print a "signature" quality. This last feature is reflected in ethnographic sources discussed below, and evidences a bringing into play of the hand image's first order of meaning, its self-referential character, i.e., its reference to its own making. Variations in the manner this prior meaning is taken up and elaborated in the case, for example, of decorated hands in Arnhem Land, Australia (Figure 2) — or put aside, which is the case with the investment of symbolic meaningwill always be of interest to researchers. What bears on my argument for proprio-performative 
reception is the way cultural differences which in any instance might be determined by placement and formal properties - including size, color, decoration, digital variations, choice of right or left hand, and association with other motifs - might influence the likelihood of hand stencils and prints being read as hands, and specifically as hands belonging to a particular individual. In due course, it will be necessary to unpack this notion of the image's particularity by reference to the further notion of stencils and prints as freeze-frames of an individual act. In the meantime, all that needs to be kept in mind is the readability of the image as a given specific hand. Before proceeding to my argument for a category of the proprio-performative, I shall deal with a range of possible ifs and buts.

Figure 2. Decorated hands, "Major Art" site, Mt Borradaile, Arnhem Land, Australia.

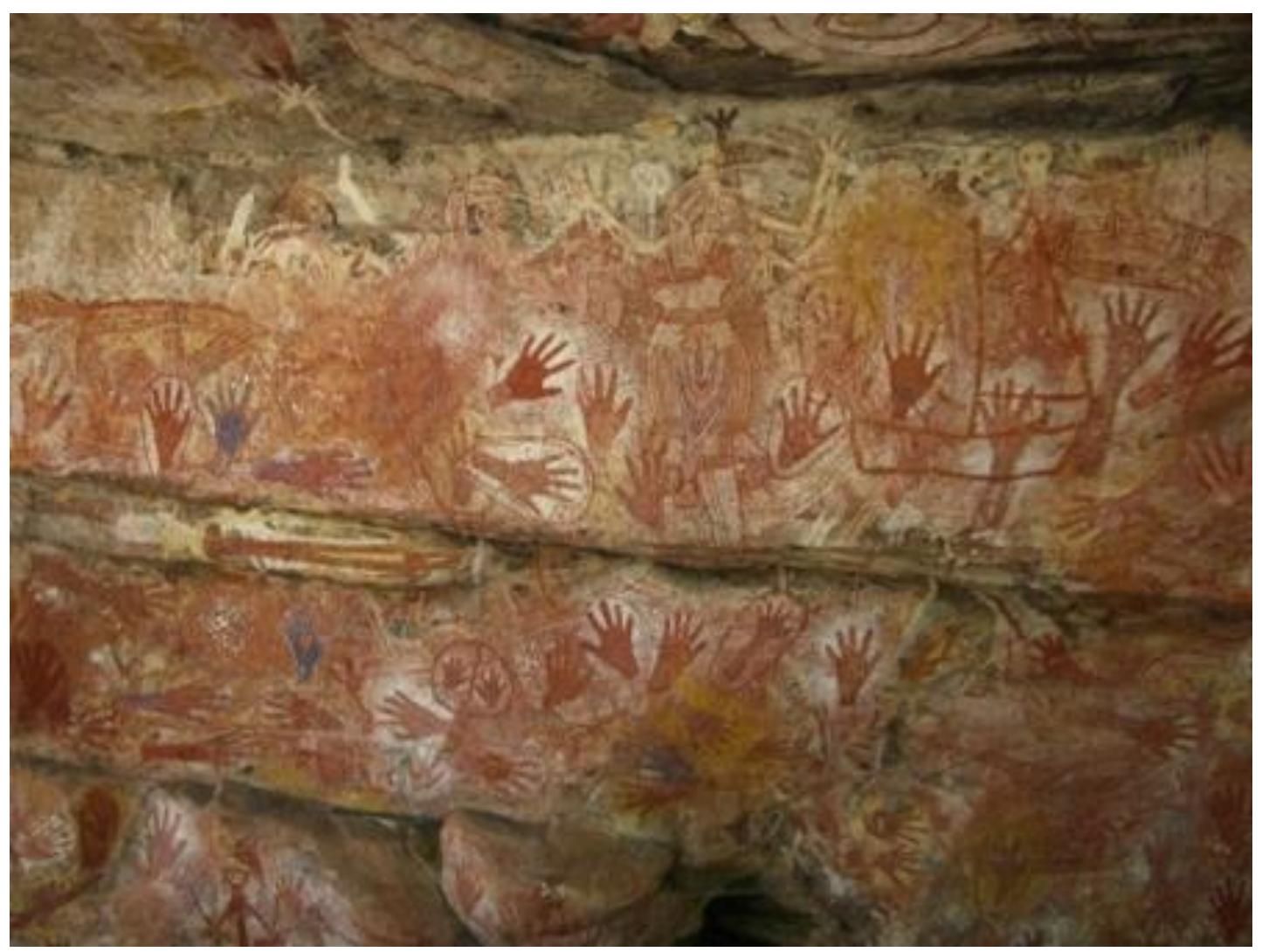

\subsection{Placement}

Cultural meaning may be expressed through the location, positioning and spatial distribution of images. At Carnarvon Gorge, in the central Queensland sandstone belt, Australia, and at Cueva de las Manos fronting the Pinturas River, in Santa Cruz, Argentina, spectacular use is made of affordant cliff faces to produce imposing panels of stenciled images, chiefly of hands. Carnarvon is notable for surfaces crowded with superimposed images as well as displays where there appears to be a purposeful arrangement of discrete stencils made, if not contemporaneously, then within a continuity frame of cultural connection. At Cathedral Cave, Carnarvon, for example, an arrangement of stenciled images around an opening in the rock might suggest ritual placement. An investiture of symbolic meaning does not, however, override a primary reading of the hand stencils as individualized hands. At Cueva de las Manos there are hand stencil panels made up of superimposed images, and others, which allow the stencils to stand out in isolation. Around the world, stencil or print sites utilizing more intimate 
spaces sometimes present themselves as composed assemblages, while at other times frequent re-inscription is evident. Sometimes the impact of an image will be accentuated through its position in a framing niche, as at Gargas where a notable stencil with shortened fingers is naturally framed ([34], p. 248, Figure 267). At Cosquer stencils displaying digital length variation are found on limestone draperies ([22], p. 71).

Universally, whether the negative and positive hands are placed as solitary register or layered palimpsest, their readability as hand marks is not affected. Indeed, in Australia, many instances have been recorded where cultural meaning is inextricably linked to the actual recognition of the maker's identity and I shall return to this when discussing the frequently-encountered notion of hand stencils and prints as "signatures" (Figure 3). Gunn appeals to Clegg's view that placement will depend on the existence of previous images [43], something observed at some Montana hand-print sites by Greer and Greer [44]. However, on the basis of observations made at central Australian sites, Gunn predicts bands of stencils occurring at levels suggestive of a correlation between the height of stencilers and hand size. Exceptions are noted, one of them being an infant's hand high up on a ceiling, which would have involved lifting of the child by an adult ([43], p. 109). Mulvaney recounts Aboriginal stories from the Kimberley of children being held up while hand stencils are made ([26], p. 14). At "Baby's Feet Cave", New South Wales, Australia, a pair of stenciled feet is included at height within a panel of hand stencils. The question of the relationship between hand and feet images and whether or not feet should be included in the proposed proprio-performative category will be considered in due course.

Figure 3. "Art Gallery", Carnarvon Gorge, Queensland, Australia. Courtesy B. Witemeyer.

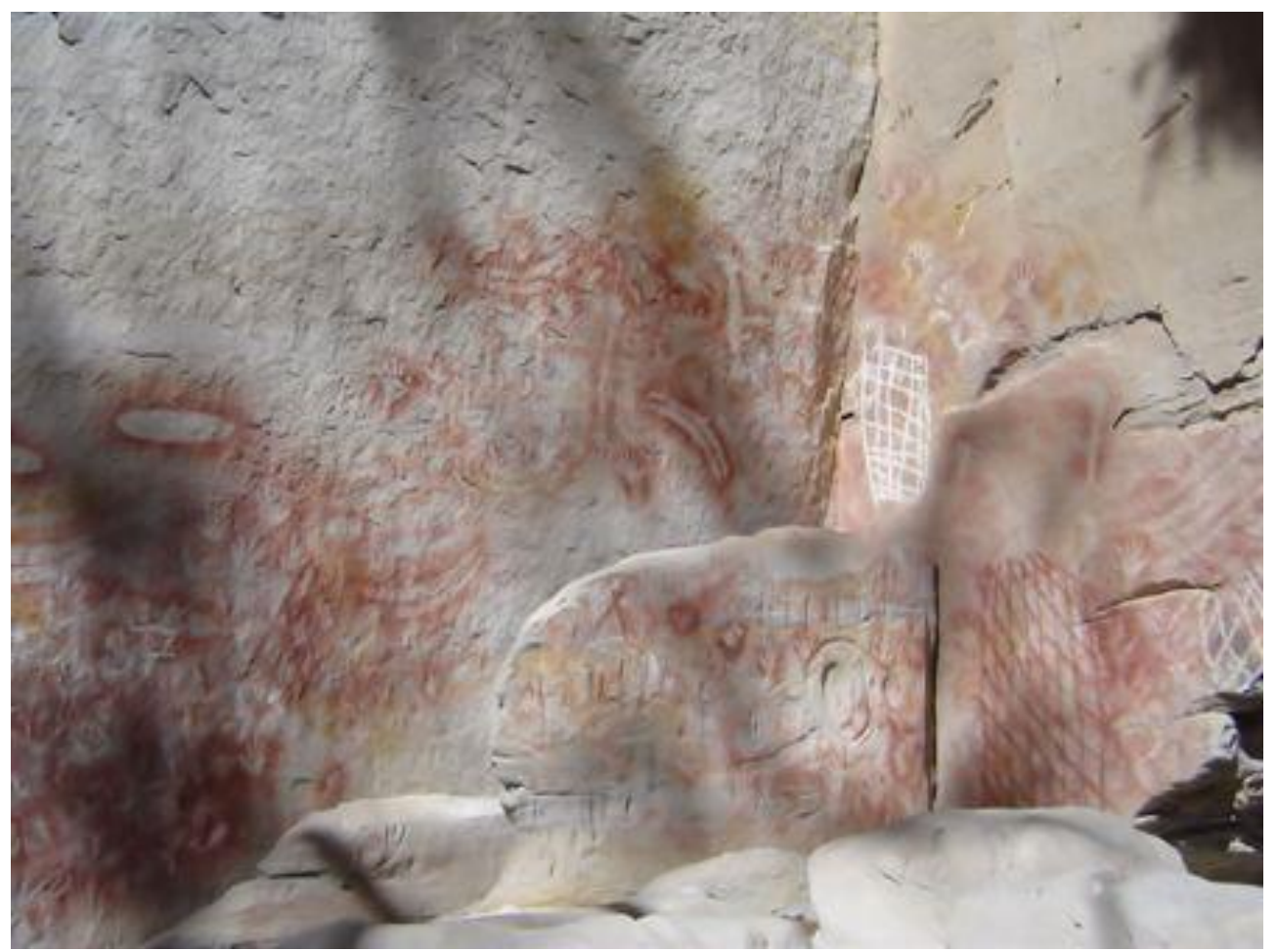

Greer and Greer suggest functions for handprints in the Smith River area, central Montana, that would appear to be defined by setting and association. Most often hands are found at "open bluff marker sites" which address those who approach them, conveying information about "trail routes, hunting 
grounds, or tribal identities". Painted in blatant color, such sites "act as a sign or a billboard" ([44], p. 69; [37], p. 171). From his survey of hands at Franco-Cantabrian sites, Leroi-Gourhan ([45], p. 58), looking for evidence of symbolic use, concludes that, in general, there is no pattern to stencil location within caves as this differs from site to site. There are many instances of hand stencils superimposed over other images in ways that suggest an intention to connect with previous images. This will be discussed under the heading "Association with other images".

Placement is discussed in the global literature from many points of view, ranging from assertions of symbolic arrangement to inquiry into the makers' stature and age. Some placements may enhance the communicative potential of hand marks, like the "framed" hand at Gargas or the central Montana displays at "billboard" sites. Documented instances of obtrusive or accentuated exhibition lend support to my argument for an immediately accessible (though culturally useable) primary, i.e., non-culture-specific, meaning.

\subsection{Size}

The only point that needs to be made in respect to size is that, allowing for distortions resulting from affine effects occurring when the hand is angled somewhat, as well as under-spray in stencil-making and smudging in the case of prints, hand traces will approximate the sizes of the hands that made them. Predictably, stencils will be slightly larger and prints smaller ([43], p. 109). This is what gives researchers license to speculate about age, sex, and stature. An important study in this regard is Gunn [43]. This reviews both the literature of hand size research in Australia and that relating to Aboriginal stature across the country. It presents the results of examining variations in the size of stencils and prints made by a single hand when compared to actual hand-size, and-from measurements taken of stencils at central Australian sites for comparison with hand morphology data collected by Tindale between 1929 and 1935 - concludes that the variability of stencil and print hand length is such as to make this comparison difficult. The length of middle fingers proved to be the most reliable predictor in the case of stencils and on this basis some separation in terms of age was achieved. Sex on the other hand could not be determined except in the case of the largest stencils (middle finger in excess of $9 \mathrm{~cm}$ ) considered to be male because there are no recorded female hands of this size (pers. comm., 22 April 2013). Measuring hand length is recommended for prints ([43]; [46], p. 322].

Bednarik applauds Gunn's caution, while pointing out the serious flaws in attempts by Chazine and Noury to sex hand stencils at a Borneo site by applying Manning's index finger/ring finger ratio [47,48]. Finger length differences between males and females expressed as the "2D/4D ratio" are sourced to prenatal hormone exposure and have been used in a variety of anthropometric studies. The ratio's possible usefulness in predicting the sexual identity and stature of the makers of rock art hand impressions was discerned by Freers [46] shortly after Manning et al. published their 1998 paper [49] on 2D/4D as a predictor of fertility. Freers' 2001 article for American Indian Rock Art outlined his procedure in testing an anthropometric methodology incorporating 2D/4D comparisons devised to sex San Luis Rey Style hand prints at a Californian site. Results appeared to validate ethnographic accounts at the same time as they pointed the way to interpretative refinements. However, Freers sounds a note of warning: "Minor deviations in positioning can readily change the designation of 2D/4D relative length" ([46], p. 330). In response to Chazine and Noury [48] and Snow [50], Manning 
himself collaborated with archaeologists to take up the challenge of "who painted the images?" in relation to palaeoart and he could not be clearer about the pitfalls of attempting to discern authorship by means of the ratio alone [51]. If it is treated as a circuit-breaker to the issue of hand-size overlap between males and females, as well as between youths and females, then the 2D/4D ratio too has a problem of male-female overlap. Other problems identified by Manning were the difficulty in achieving accurate measurements of stenciled hands and controlling for ethnic differences in the process of establishing a normal range. Manning was not confident that the "sexing software" $\left(\right.$ Kalimain $^{\circ}$ ) developed by Noury could avoid compounding measurement problems. The Manning article is invaluable, not only for its specific critique, but for confronting general issues relating to hand sites, such as possible sources of dimension distortion in stenciled hands, artwork representing different time frames at the same site, or ambiguity relating to right hand/left hand identifications - right hands being more indicative of ratio difference.

The use of 2D/4D is ongoing, despite the efforts of Brůžek et al. [52], in the specific context of critiquing Chazine and Noury [48] and Snow [50], to dissuade people from trying. They argue that, without knowledge of the population in question, hope of determining sex is "illusory" [52]. At this point in time, Freers continues to pursue his project of bringing together ethnography and anthropometric data obtained in part by 2D/4D for a determination of author-profiles: both stature and sex [53]. Using an updated version of their software and continuing to appeal to Manning's ratio, Chazine and Noury are engaged in producing further predictions for Borneo sites [54]. Robins and Nowell have taken up Manning's suggestion of replication studies to test the useability of 2D/4D. A sample of 400 children using blow pipes has produced positive results in terms of accuracy when the ratio measured from soft tissue is compared with that of stencils. However, the challenge of addressing the issue raised by Brůžek et al. [52,55] remains.

Large or small (Bednarik claims juvenile authorship for Franco-Cantabrian cave art [47]), robust or gracile (Neanderthal authorship is hypothesized at El Castillo [23]), male or female, the issue for the present argument is, however, simply the readability of images as hands. As indicated above, and crucially for the proprio-performative thesis, hands are read as belonging to someone-whether or not that someone can be identified. This is the assumption behind all efforts to judge characteristics through stencil and print measurement.

\subsection{Color}

Use of color has been around for a very long time, for body decoration or other purposes. On current sub-Saharan evidence, Beaumont and Bednarik tentatively postulate pigment use arising as much as a million years ago [56]. Africa certainly has the most abundant and oldest safe evidence of pigment use. At Wonderwerk Cave, central South Africa, a richly-productive site with evidence of occupation from 800,000 to 900,000 years ago, pigment material of possible $\sim 1.1$ Ma age has been found ([57], p. 44). Sites in Kenya and Zambia support African antiquity ([58], p. 96), and in this issue of Arts, Bednarik underlines the importance of evidence of haematite traces on the significant middle Acheulian Tan-Tan figure from Morocco (see also [58], p. 96; [59]). A find of 100,000 year-old shells used in the mixing of ochre at Blombos cave, South Africa [60], evidences early human art activity as well as cultural continuity with the present. Mulvaney ([26], pp. 15-17) gives a detailed account of 
recently-recorded ochre-gathering practices carried on in the Kimberley, Australia, including the use of boab nut containers for pigment preparation. For the elaborate procedures of Arnhem Land, Australia, see the "Pigments, brushes and techniques" section in Chaloupka ([61], pp. 83-86). The relevant question here is: what does color bring to hand stencils and prints? Bahn and Vertut ([36], p. 169) observe that the palette of European Palaeolithic art "was limited and usually involved a straight choice between red and black". Petru adds white, while allowing for the disappearance of unstable color (Bednarik's "taphonomic logic"). She remarks pertinently: "If elaborated speech emerged with modern humans, then improved communication through color is probably part of modern human behavior" ([62], p. 204).

At the polychrome hand stencil site, Cueva de las Manos, color is amazingly varied in its white, black, yellow, red, violet, and occasional green effects (for pigment analysis see Wainwright et al. [63]), and exuberantly displayed in what in some instances could be non-accidental placements. For example, situated above crowded panels, as if to attract special attention, is a single hand stencil in green (Figure 4). Gradin et al. ([64], pp. 18-19) speculate that specific colors might have been used to identify membership of a tribal group. This is the case for color use in Arnhem Land where the privileging of particular colors relates to "group expression" as well as individual seniority ([61], p. 86).

Figure 4. Cueva de las Manos, Santa Cruz, Argentina. (For green stencil see top centre.)

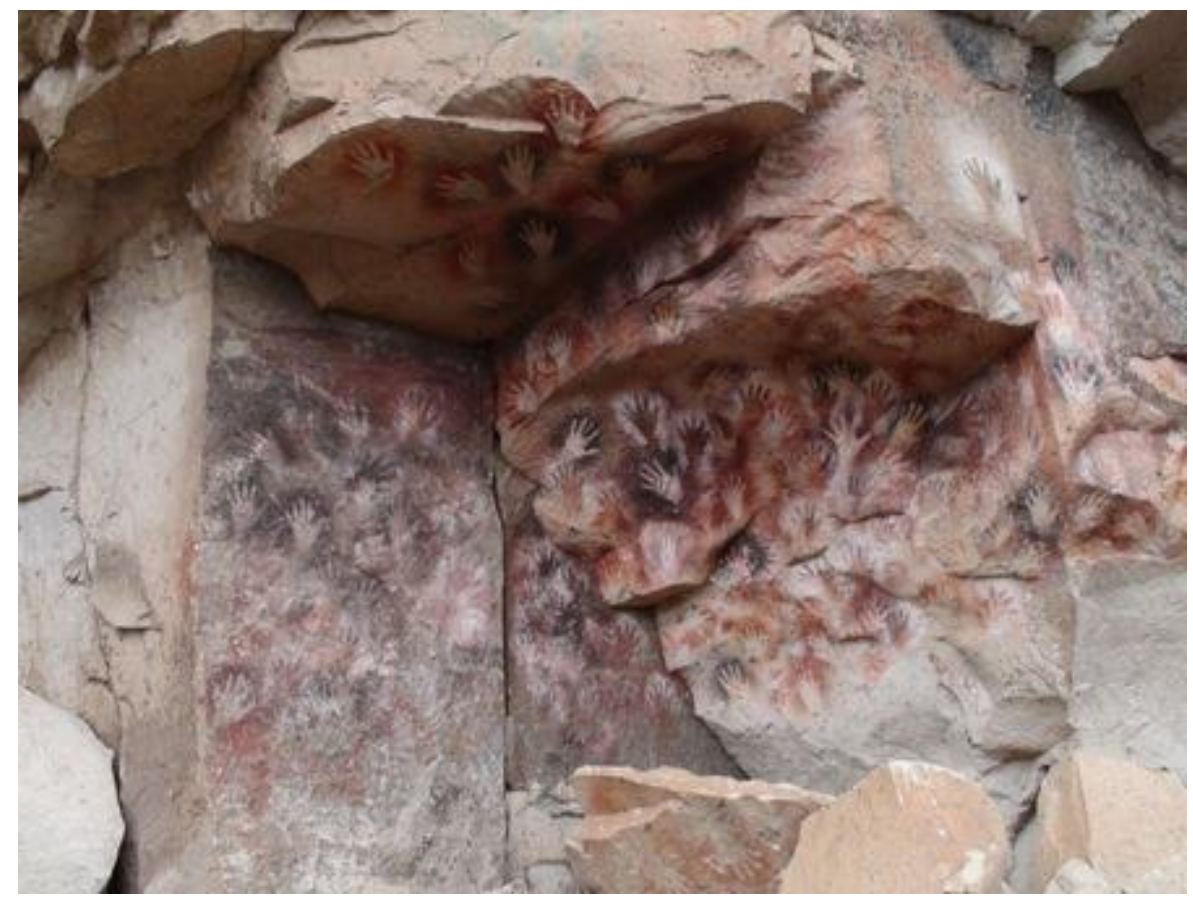

Leroi-Gourhan hypothesizes symbolic alternating red and black color use for stencils at Gargas [65]. Some sites, like Carnarvon Gorge, feature only one pigment, in this case mostly red applied to greyish white sandstone walls. Tresize notes a replacement of red hand stencils by white, suggesting highly speculatively a "taboo", in Quinkan country, Cape York, Australia, occurring "when people were able to return to country abandoned to searing drought for many millennia" ([42], p. 199). Color is, of course, a feature of positive prints as much as stencils, as the 100 Hands site in Utah illustrates, inviting similar conjecture about the reasons for its use (Figure 5). 
Figure 5. Positive prints, 100 Hands site, Utah, USA.

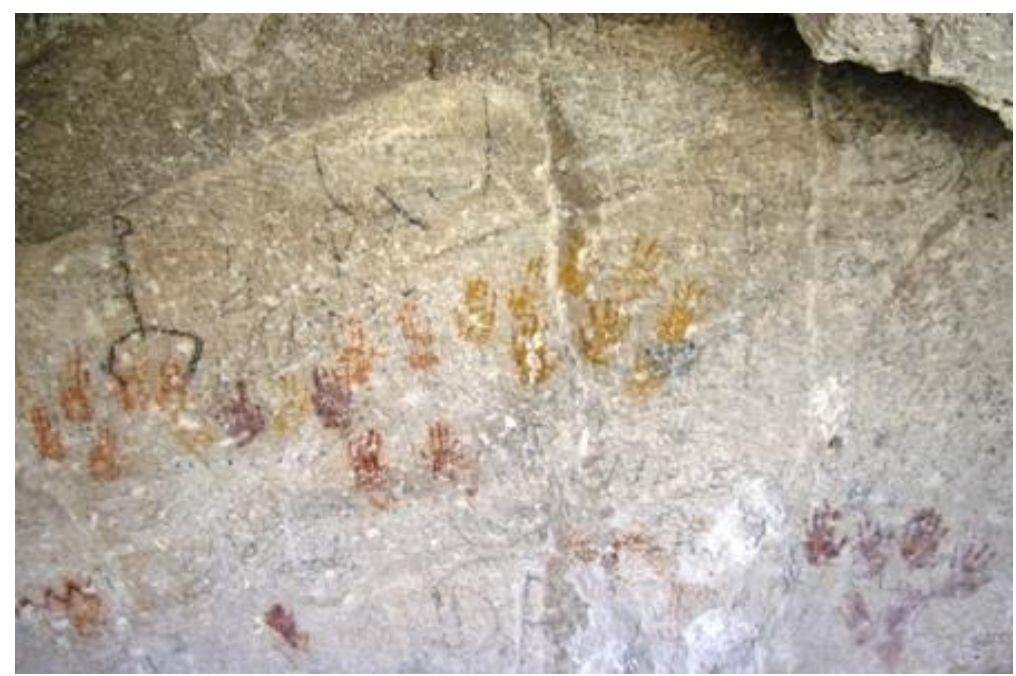

Does color, then, interfere with what I have termed primary hand readability? The answer is clearly "no". A hand mark records a specific hand regardless of the color of the pigment used, and at Cueva de las Manos, despite variety and profusion in hand presentation, there are many indications that, over and above apparent compositional arrangements, the single mark was important in its own right. Even where stencils are placed on surfaces already painted-cthus leaving a beautiful polychrome effect" ([39], p. 27) - there will be those that still stand out in sharp relief against the palimpsest background with its elusive specters of past stencil applications (Figure 6).

Figure 6. Cueva de las Manos, Santa Cruz, Argentina.

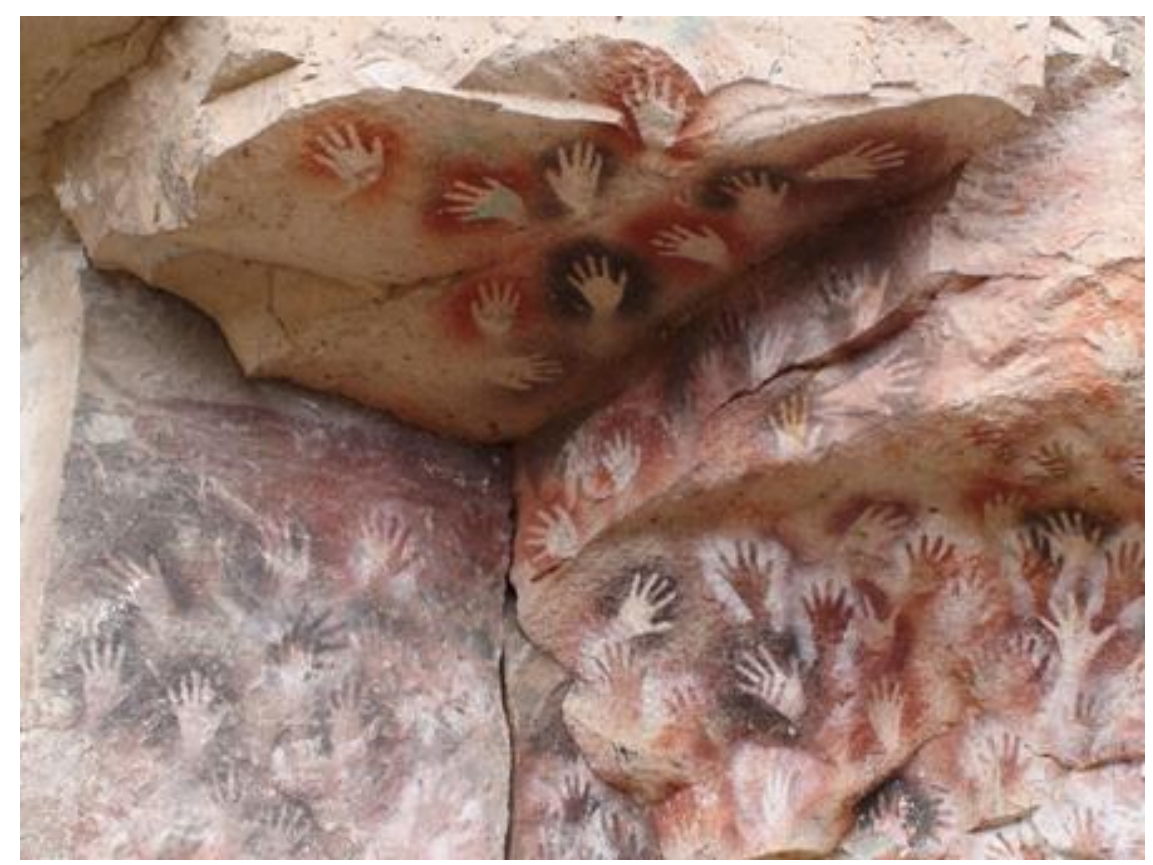

An issue arises for the present argument when the so-called "decorated hands" of western Arnhem Land are considered. At "Major Art" shelter at Mt Borradaile, Australia-also notable for an abundance of superimposed hand stencils in striking color-original negative images have been transformed by the addition of intricate designs. The idea that color matters in this process is 
reinforced by the use of "Reckitt's Bag Blue" (i.e., washing blue obtained from missionaries) in place of ochre for some hands, thus extending color range. Chaloupka ([61], p. 214) describes similarly embellished hands found at other locations in the region, claiming that the decorative tradition stems from representations of gloves observed during the contact period. Other representational options, however, are not ruled out, and another explanation for such "glove-like" images has been offered by Taçon who draws on information from Arnhem Land supplied by Cannon Hill's Bill Neidjie on the subject of repainting extant stencils of the dead: "some stencils have been painted with clan designs and x-ray features, such as finger bones, to produce striking images by which to honor and remember particular individuals" ([66], p. 138). The practice in southern Arnhem Land is to obliterate pictures, including stencils, made by the dead by over-painting them with red ochre before replacing them with fresh images. If this does not happen, then "the original picture must be left to wear out" ([67], pp. 245-246). We can conclude from this that in all instances the likely motive is to remove traces of individual identity. However, in the case of such "decorated hands" we do not need ethnography to tell us this, as it is a matter of perception. Although hand size will continue to give some indication of owner identity, attention to the potently-evocative facsimile of the originator's hand recedes. It is for this reason that this sort of image is, as I intend to argue, to be excluded from the proprio-performative category. Once decorated, and depending of course on the nature and extent of the decoration, the hand image no longer addresses the viewer in the same way. It is no longer a trace, but a picture of a hand (Figure 7).

Figure 7. "Decorated hands", Mt Borradaile, Arnhem Land, Australia.

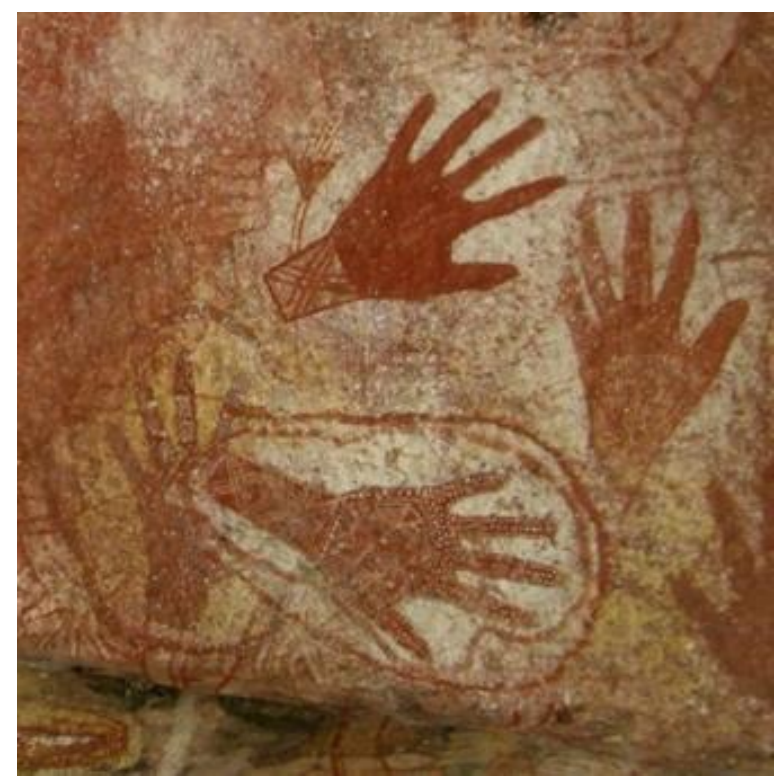

\subsection{Decoration}

With decoration, there is a point at which the very particular trace of an individual hand disappears. In the Australian case given above, the stencil is now altered and in such a way that it has not become, by virtue of the infill, the equivalent of a print. A print is as readable as an animal track encountered in real life. With the cues for individual ownership weakened or erased, the adorned hand is aptly described as "glove-like". Embellishment functions as a mask, or, to use a culturally-loaded word with 
different color connotations, a "shroud". Its function is to cover over. In a word, the stencil looks less like a stencil and more like a picture. However, it is essential for a stencil that it not be a picture, even as it retains that iconic quality.

Another version of the embellished hand is to be found in the enhancing of a positive print. This is the "patterned hand" encountered in Australia and elsewhere (Figure 8). In this case, the patterning is not so much an obscuring of the original hand image, as a visual distraction. Prints "with an unusual form of internal decoration" at Levi Range, central Australia, were examined by Gunn [68]. Various hypotheses were put up and actually tested, with the result that similar images to those at the site were replicated by "scraping" onto the "pigmented hand". The Levi Range positives are remarkably similar to those of Canyon de Chelly, Arizona, recorded by Grant. These are said to be achieved by "drawing whorls, zigzags, and straight lines on the wet palm with a stick" prior to printing ([69], p. 158, Figure 4.7; p. 169, Figure 4.17). Manhire describes "decorated" hand images, "somewhere between a print and a painting", from the south-western Cape, South Africa, made "by scraping off a pattern, usually nested curves or "U" shapes, on the already paint smeared palm or hand" ([70], p. 98, p. 99; see also van Ryssen [71]). Malotki and Weaver distinguish between "stylized" (i.e., nested U's), lined or "striated", and "patterned" positives (bearing scrolls, checks and zigzags) — and give examples of these from the American southwest ([72], pp. 54-55). "Stylized" for Greer and Greer is something different again, involving distortions of shape. They also remark that, at one Montana site on the Musselshell River (Reighard), after application of paint to the wall, "many had the palms (and sometimes the fingers) pecked out by a small sharp object" ([44], p. 63, p. 67). Bahn provides an illustration of the "nested arc motif" on prints at Seminole Canyon, Texas ([73], p. 112). Unusual hand images from Esselen Big Sur country, California, have been documented by Breschini and Haversat. While these look like patterned prints, however, careful examination suggests they have been "painted using a brush" ([74], p. 142).

Figure 8. "Patterned hands", central Australia. Courtesy R.G. ("ben”) Gunn.

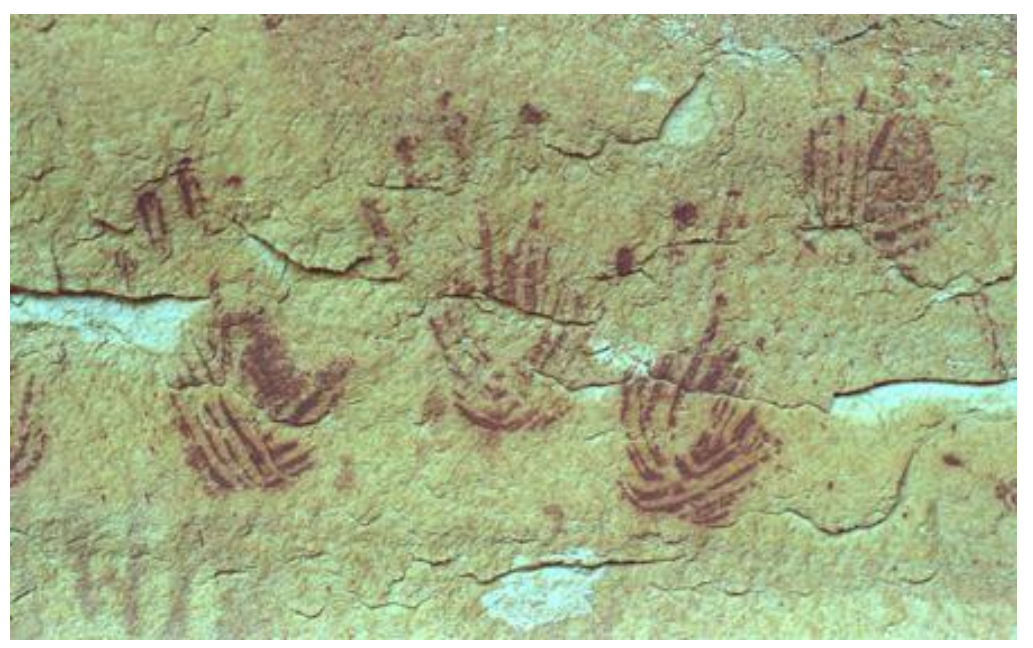

What is important is that-as with decorated negatives-canonical form, i.e., the recognizable shape of the human hand, is not overridden: crafted positives still remain recognizable as images of human hands - despite any fuzziness due to smudging or dribbled ochre. However, the effect of the patterning is to suppress the prints' readability as individual hands in favour of attention-grabbing 
display. This sets patterned positives apart as a collection of distinctive images referring to something over and above both their individuality and their general readability as hands. In fact they appear to lend themselves to group (clan/moiety) identification. Clan identification has also been suggested for decoration resembling body-painting within stencil outlines found at some Borneo sites [54]. In this case the stencils' personal forms are not obscured. Likewise, suppression of identity cues need not come into play when the vacant area in the centre of a print is simply filled in "to make it more homogenous and complete" ([44], p. 62). To sum up: the masking of an individualized act which comes into play in the case of decorated negatives and the element of visual distraction with patterned positives will affect the way such images are viewed when considered as candidates for inclusion in the proprio-performative category. The full significance of the notion of stencils and prints as the record of an action will emerge in due course.

\subsection{Digital Variations}

Breuil on Gargas hand stencils: "Many seem to be mutilated as if phalanges had been cut off" ([34], p. 256). Because of its centrality in the discourse, we are obliged to begin with the theory of deformed (either "mutilated" or diseased) hands - dated as it might be. Reports of finger amputations in Australia were made in the colonial period (e.g., Tench in 1789, [75], p. 49; Collins in 1798, [76], p. 458) and by later ethnographers like Roth ([77], p. 184) and Basedow ([41], pp. 253-254) - in 1897 and 1925, repectively - and may have contributed to the mutilation thesis. Finger amputations were in fact referred to as "mutilations" by some early anthropologists ([78], p. 746). Grant ([69], p. 168) accepts it unquestioningly, while Bahn ([73], p. 113) simply states pro and contra viewpoints. In 1967 Leroi-Gourhan complained that the mutilation hypothesis, "acceptée par la majorité des préhistoriens... est passée dans la tradition scientifique, sans verification approfondie" ("accepted by most prehistorians and... passed into scientific tradition without being subjected to strict verification"). He put up arguments against both mutilation and the idea of pathological deformation ([65], p. 108; [79], p. 20). Opinion did change, however, and since lengthy discussion of the limited practice of ritual amputation in Australia ([80]; [81], p. 14; [82], pp. 3-4), replication experiments (Groenen [83], pp. 101-111; see also Walsh [80]), and the instancing of transposable signals from gestural languages of the Kalahari and Australia ([84], p. 215; [80]), most commentators have come to accept that, for the most part, digital variations have been accomplished by bending fingers and were used to codify symbolic meaning [65]. Reviewing what began as a heated, largely French debate, Clottes and Courtin ([22], pp. 67-69) put forward a strong argument against the idea of mutilated or deformed fingers in favour of Leroi-Gourhan's "transposition directe des symbols gestuelles du chasseur" ([65], p. 121). They illustrate just how speculative the theory always was by pointing to the fact that "no skeleton known from the upper Palaeolithic displays hands with incomplete, amputated, mutilated, or deformed phalanges" ([22], p. 67). We have witnessed the same turnaround in Australia with Morwood asserting confidently that "partially missing or distorted fingers are clear manipulations of hand position, as used in historic times for sign-talk during hunting or periods of enforced silence" ([85], pp. 166-167).

It has been pointed out that it is difficult to match static stencil images with the dynamic signs (Figure 9) which occur in gestural language [82,86]. 
Figure 9. Samples of gestural signs denoting birds, reptiles and fish, as illustrated by W. E. Roth, Plate IV, Ethnological Studies among the North-West-Central Queensland Aborigines, 1897.

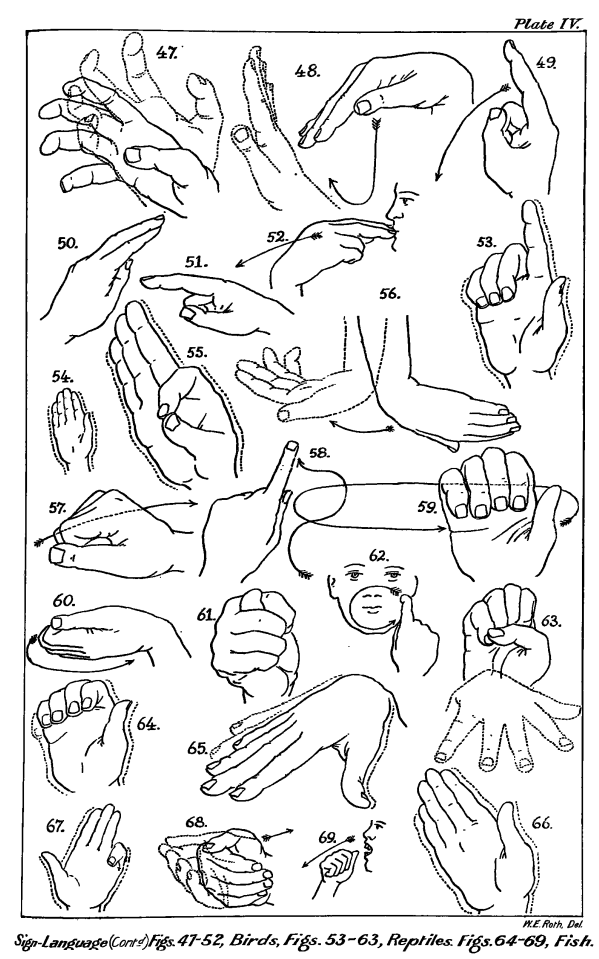

Nevertheless this is what Walsh [80] managed to do with some degree of convincingness. One illustration from central Queensland of what we should be now willing to call "transposed sign language" will suffice to show the kind of images for which Walsh was seeking to find gestural equivalents (Figure 10).

Figure 10. Candidate stencils for transposed gestural signs, Central Queensland Sandstone Belt, Australia. Courtesy C. Sefton.

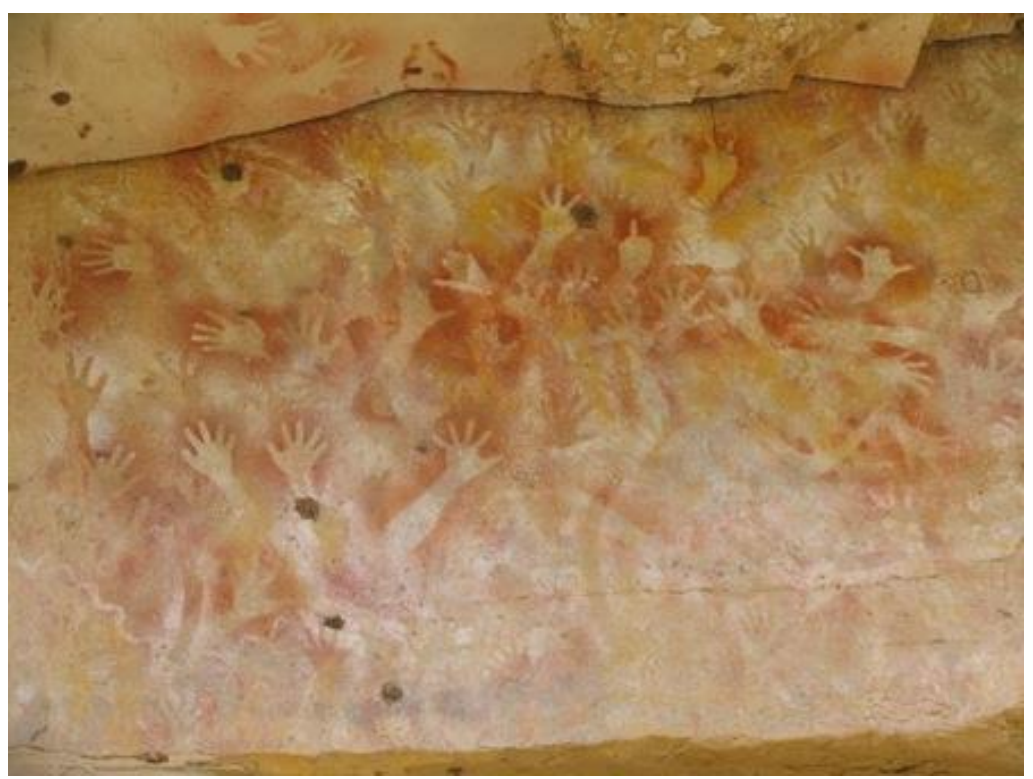


I have not been able to match images from this panel displaying digital variation with the Roth illustrations ([77], pp. 71-90; Plates II-X) Walsh draws on for comparison, except perhaps for his "b", visible as a hand with one finger extended upwards (Figure 11), which Walsh himself appears to think matches a Roth figure (his Figure 143. Spear: Wommera-spear [77]). Wright [82] extended Walsh's exercise by making a comparison of stencil variants encountered in western central Queensland with signs denoting faunal totems recorded in six source texts, including Roth (Figure 9). His conclusion was that such signs feasibly account for around $40 \%$ of his sample and, conversely, that mutilation accounts for less than $9 \%$. From such investigations we can allow that there exist a number of images which are quite distinctive in shape and might qualify as signs. However, their meaning as signs cannot be verified without cultural knowledge. We can only guess, like Walsh using available ethnography from an area $600 \mathrm{~km}$ distant, and Wright from even further afield. We need not conclude that all meaning will elude us, that we cannot " "read' rock art" [87], for we can recognize stencils as replicas of hands even when they refer to gestural signs, and this is what is important for my argument. Hand stencils are universally understood as hands. As traces of hand actions they are as recognizable as animal tracks, even when fingers are bent. With digital manoeuvring we see a hand with contorted fingers and additionally see the canonical form of e.g., a bird's head. And if we are proficient in a gestural language we will read and decipher any supererogatory meaning invested in a particular configuration of bent fingers, canonically suggestive (like the bird's head) or otherwise.

Figure 11. G.L. Walsh, "Mutilated Hands or Signal Stencils?". Australian Archaeology 1979, 9, p. 35. (Example "b" is seen top right.)

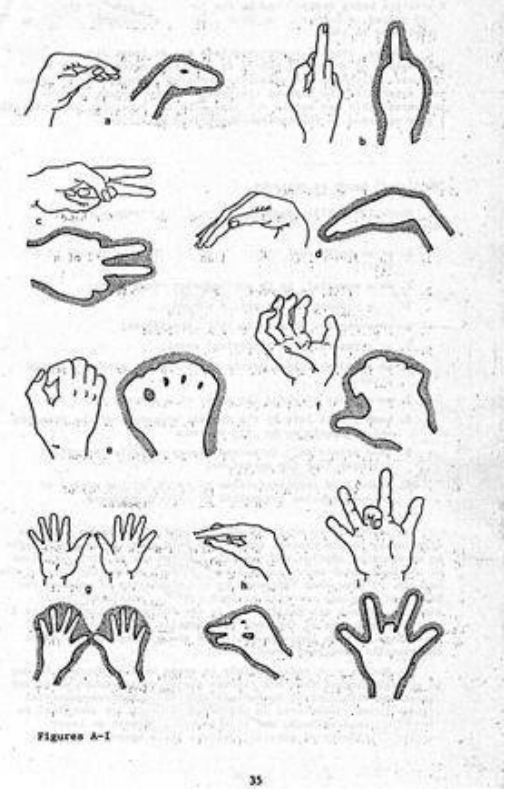

To return to the example of the single-fingered stencil (Figures 10 and 11): there will be exceptions to hand recognizability. Excised from its context, Walsh's Example "b" might not be recognized as a hand without ethnographic input, but this particular image presents an extreme case of occluded elements which could cause it to be confused with other shapes. That our perception can at times be bamboozled does not alter the fact that we rely on it to negotiate our way in the world. Habitually we recognize hands in numerous postures - with bent or folded fingers - and it is not more difficult to 
detect their forms in the stencils than it is to recognize hands in real life. Therefore, with the proviso that we can suppress our awareness of the canonical form of hands, that is, their recognizability as hands, when switching our attention to symbolic meaning - or when attending to a canonical alternative of the bird-head variety - hand stencils retain their own iconic status, retrievable at any moment.

Demonstrably, in the absence of other markers, their function as communication from an individualized source depends on their recognizability as hands. At the same time, with these and other examples it is a case of "a particular someone saying this". Regardless of digital variation and its possible symbolic import, individual traits (hand size etc.) are apparent, which means that a reading of individual identity, even if unspecified, is part of the meaning. I suggest that while ethnography cited below may allow us to specify identity, it is the fact of the stencil's individuality, rather than actual personal identification (presupposing cultural knowledge) which is of interest to the present argument.

\subsection{Choice of Right or Left Hand}

This record of the making of a hand stencil by anthropologist Daisy Bates was made between 1904 and 1912, although it had to wait until 1985 for publication by the National Library of Australia:

In drawing the white hand, charcoal or red ochre is softened or moistened in the mouth and the clean bare hand pressed against the surface of some white or light colored rock, with the fingers of the hand well stretched out. The charcoal or ochre mixture is then blown or squirted against the back of the hand and well between the fingers and thumb and when the hand is withdrawn a perfect impression is left on the rock, enhanced by the dark surrounding of red or black as the case may be ([88], p. 272, italics mine).

Bates distinguishes between colored images in black or red, and white images. All are called "impressions", but it is clear that by "drawn" white hands she means stencils. There has been an issue in rock art studies as to whether the palm or back of the hand is used to make stencils ([89], pp. 99-100; [33], p. 50; [22], p. 70; [44], p. 61). Like Bates as quoted above, Basedow also specifies palm-to-surface in stenciling by spraying from the mouth ([90], p. 238). What both have to say about this matter is given support by a remark by Flood to the effect that contemporary Aborigines place the palm against the surface ([91], p. 103).

When rock art researchers record a predominance of left hands (which is almost always the case), they are assuming on an intuitive basis what Bates, Basedow and Flood claim from observation, viz. palm-to-surface application. Layton ([25], p. 75) inadvertently supplies pictorial evidence to support this view with his photograph of the maker of a stencil identifying where she put her hand on the rock.

Assuming the jury still to be out on the issue of palm-to-surface, Clottes and Courtin ([22], pp. 69-70) sensibly choose to call a left hand one whose the thumb turns to the right. Adopting this as a convention allows us to bypass the issue of palms or backs of hands. Clottes and Courtin go further than this, however, by suggesting that at Cosquer and Gargas the "form of the images" rules out the dorsal possibility. By closely examining an awkwardly-placed hand image at Gargas, Barrière and Sueres set out to dispose of the notion of the right or left hand applied dorsally to produce the effect of its opposite. Clearly the orientation of a depicted wrist or arm will help in making a judgment in a specific instance. Where the sceptically-proposed "inversion acrobatique" of Barrière and Sueres 
would have to be assumed for back-of-the-hand execution, we are surely justified in ruling it out ([33], p. 50). Nevertheless, we can never be entirely certain. For argument's sake this stencil from Mt Borradaile (Figure 12), unusual in having the thumbs turned outwards (cf. the more commonly found paired hands with thumbs turned inwards), might have been achieved by putting the right hand to the wall to produce the stencil on the left-hand side, then flipping it on its back for the one on the right. Alternatively, arms might have been crossed in the making of this atypical image. Judging by the position of the wrists this seems more likely.

Figure 12. Paired stencils with thumbs outwards, Mt Borradaile, Australia.

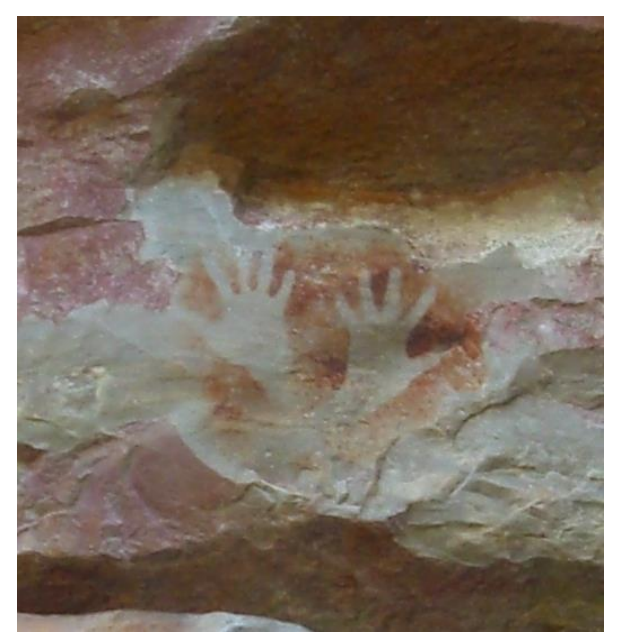

I have raised this issue merely to put it aside as irrelevant to my argument, for the simple reason that my focus is what we perceive when confronted by such an image. Whether or not the image is produced by the back of the hand or palm facing forward, the canonical form of a hand is produced and the image is thus recognizable as a hand. To state the matter more precisely: because the canonical form resulting from a left hand placed palm-to-surface and a right hand in dorsal position is exactly the same, and in being exactly the same can be read either as a left hand with back to viewer or a right hand viewed frontally, the question of whether an image was made with a left or a right hand is immaterial. (The exercise can be thought through beginning with the right hand palm-to-surface.) To say this is to argue that with stenciled hands we are encountering an effect where an ambiguity is routinely present and a perceptual switch is a routine option. For a discussion of the operation of reversal mechanisms see Dobrez and Dobrez [92] on the subject of Kihlstrom's Arizona Whale-Kangaroo (a version of the celebrated Rabbit-Duck), where the perceptual response to an ambiguity is analogous to the hands case - although the case of hands does not involve a lateral switch.

Consider for a moment my relationship with my own shadow, viz. what I see when I look at my own shadow. When I observe the silhouette of my body cast in front of me in a certain posture-for argument's sake, with arms raised and palms facing away from me-I can match the silhouette with the position of my own body and observe how my thumbs are turned towards it. When I do this matching exercise I am seeing myself from the back, as someone would see me if following behind. On the other hand, we all know the colloquial expression "afraid of her own shadow". This idea involves more than the metaphor which has been extensively used in literature to convey the notion of psychologically double or split personalities (e.g., Dr Jeckyll and Mr Hyde), for fear of one's shadow 
is an actual perceptual possibility having cognitive ramifications. If I were to approach a wall, with the illumination still behind me, my own image would loom up before me and, in this moment, I would face myself as other. Regardless of the effect it might have on my amygdala, what is important is that now a reversed image of myself appearing to me as an other confronts me. In other words a perceptual switch causes me to see my left hand as a right one facing me, and my right hand as a left one facing me. This could be labelled the "mirror effect", but shadow is a much better analogy, since with a mirror there is never the possibility of a back view, the optics being different in each case. This said, once the shadow of my hand or, by analogy, the stencil trace of my hand on the rock, is viewed as confronting me, I do then experience the mirror effect, now meeting myself as other. I shall return to the notion of a "perceptual switch" when elaborating my argument for the proprio-performative.

\subsection{Association with Other Motifs}

One outcome of Wright's inquiry into the relationship between hand stencils and sign language was the raising of an important question about the significance of associated images. Davis, commenting on Wright [82], pointed out that "associations are a central aspect of hand imprinting in Franco-Cantabrian parietal art" ([86], p. 17). Responding to this, Wright agreed that "an interpretation derived from a motif in isolation from other motifs with which it is associated, may lead to a misunderstanding of both the context and the symbolism within the artistic system" ([82], p. 17). With regard to central Queensland sites, Walsh speaks of "composite panels comprising 'signal' stencils, boomerang stencils and occasional sets of stenciled animal feet", drawing the conclusion that they are "so strikingly obvious in their composition and semi-isolated positioning" they must carry "specific" meaning ([80], p. 39). In other words, we are to see the association as extending the range of the sign system (Figure 13).

Figure 13. Walsh's “composite panel” examples from central Queensland, Australia.

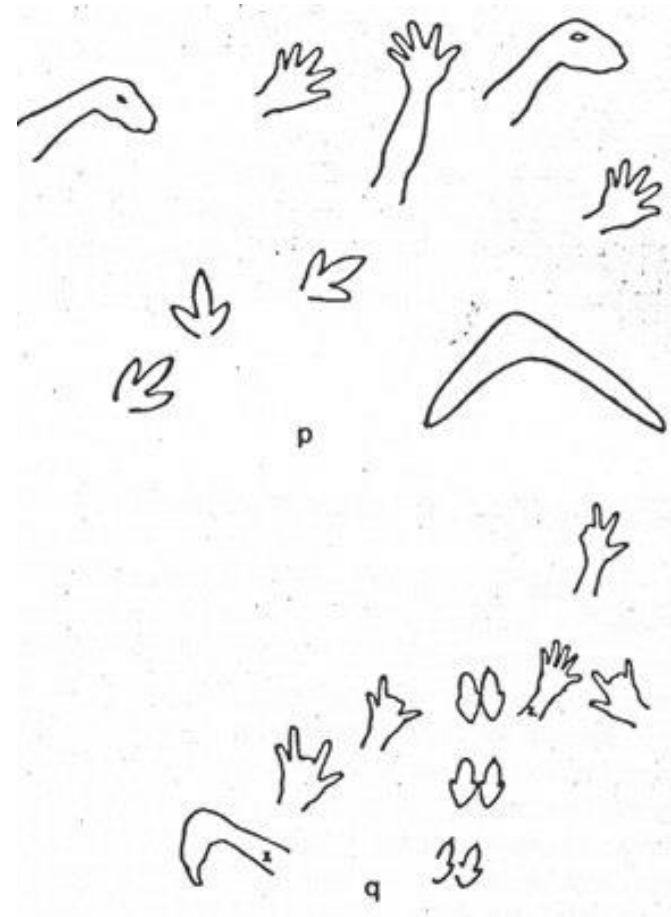


Carnarvon stencil corpora include transposed sign language hands comprising "stock" hands, hands with forearms (among such images there are conjoined forearms with hands at either end), hands with bent fingers, feet, and other objects, generally of intimate use, viz. of the "bodily auxiliary" class theorized by cognitive psychologists, Tsakiris et al. ([93], p. 657): weapons, tools, utensils, pendants, and, in a departure from the method producing iconic trace, nets made by building up the image from triangles formed by spraying ochre between two fingers. However, a layering of stencils mostly forbids the disentangling of possible associations.

At Pinturas River sites, Patagonia, stencils include choique (Rhea Americana) feet, guanaco hooves and human feet ([64], p. 19; [39], p. 29), in panels where there are also hunting scenes, geometrics, static animals in profile and frontal anthropomorphs. Analysis of superimpositions, considered in relation to archaeological evidence and pigment analysis [63,94], has enabled construction of a sequence stretching over more than 8 millennia. The occurrence of stencils placed over animal figures might lead us to speculate that these are sites of increase. Illustrating their point with an image of hand stencil superimposition on a guanaco, Onetto and Podestá speak plausibly of a "revitalizing" of panels over a lengthy period ([94], pp. 73-74). Lest we always arrive at this conclusion about motives for superimposition, Mulvaney provides an illustration from the Kimberley, Australia, of the way hand prints placed on human figures may have been used at a site for negative effect, viz. defacement: in one instance positives, in the form of both hands and forearms, are placed over a figure "on a single axis (elbow joint to elbow joint)" ([26], p. 17).

Associations of hand stencils with an imposing human figure and other objects, viz. the drawn profile outline of a kangaroo, no longer visible, "two tomahawks, a waddy, and three boomerangs", at a site thought to be a ceremonial (bora) ground at Milbrodale, New South Wales (Figure 14), were recorded by Mathews in the 1890s ([95], p. 90-91; [96]). Pigment analysis is needed to establish a relationship between the giant "Baiame" (Sky Hero) and the stencils, one of which is clearly superimposed on the figure. Indeed, it is quite possible that at this site we are looking at two distinct episodes. This would not, however, preclude intended association. Moore observes that the stencils are "positioned very deliberately" and-unlike many "jumbled and superimposed stencils" in the region-appear "to tell a definite story" ([97], p. 320). With some echoes of Howitt ([78], p.388), Elkin [98] or Eliade [99] on the subject of medicine-men who can "fly", he proposes a rather extravagant and unlikely reading of the association based on the acceptance of a dynamic and naturalistic relationship between images. Such a relationship is not generally claimed for composite stencils:

The white stripes, which have puzzled most viewers, seem to be dangling from the arms like wing feathers. If my assumption is correct, then the boomerangs are obviously being thrown at this awe-inspiring figure by the stencilled hands ([97], p. 321).

While most of the Milbrodale imagery described by Mathews is still apparent, and therefore open to future clarification, accelerated deterioration through dust pollution is deplorably imminent, as AGL Energy Limited is planning a core hole, access tracks, and infrastructure for coal seam gas exploration a mere $1.4 \mathrm{~km}$ to the north of the shelter [100]. 
Figure 14. Milbrodale Baiame with associated stencils including hands, central Hunter Valley, New South Wales, Australia.

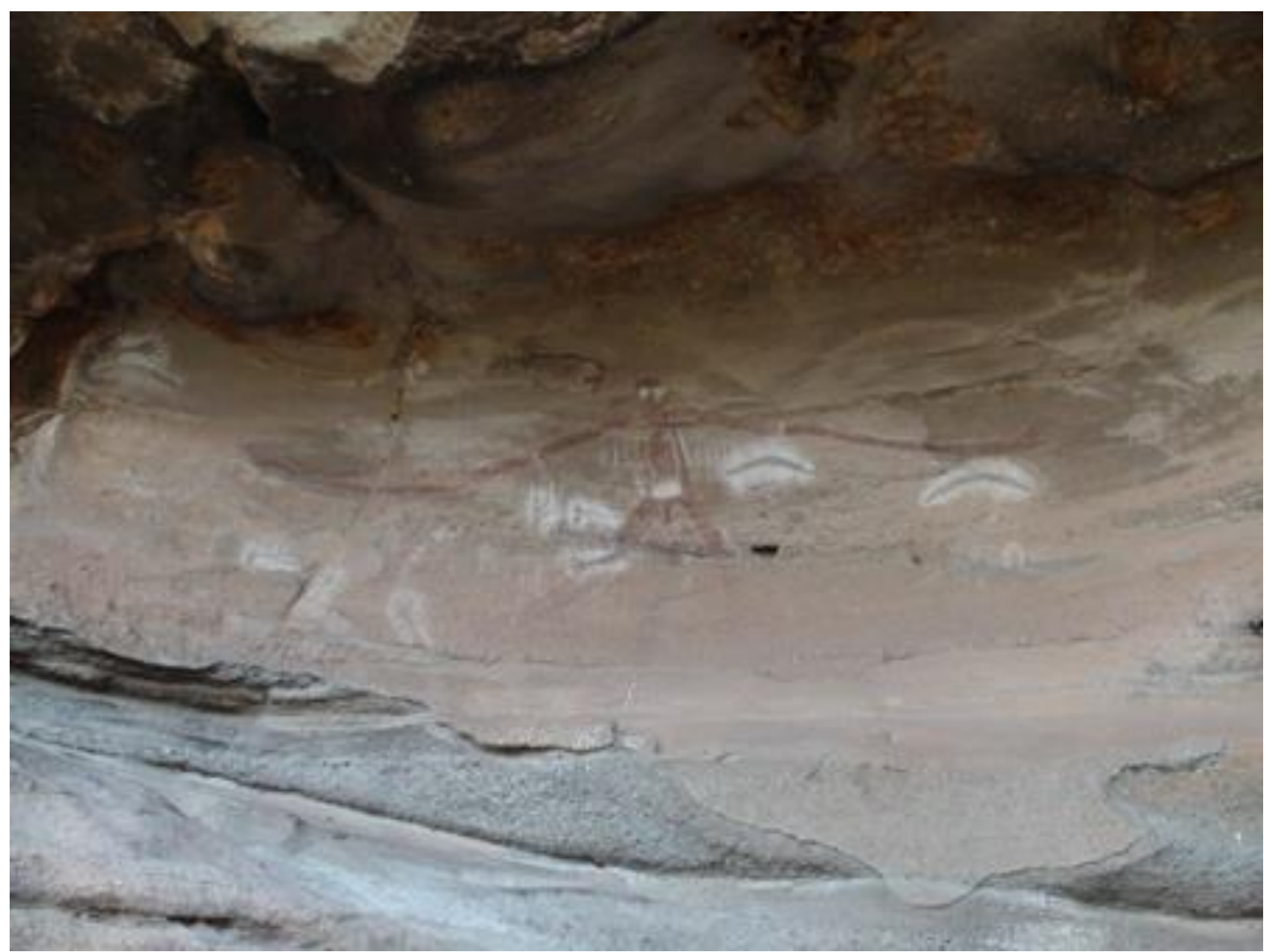

There are many examples from around the world of associations involving varied superimposition (Figures 15 and 16). Describing the extraordinarily layered "lady of the Deighton" panel in Quinkan country, Cape York, Australia, Tresize notes that "three white hand stencils had been placed on or near her body" ([42], p. 110). These, along with other painted images and pecked grooves, suggest many visits over time, some of them purposefully registered. Keyser and Klassen remark on a notable X-ray grizzly bear with surrounding and superimposed handprints at Whitetail Bear site, Montana ([37], p. 159; see also [44], pp. 65-66, p. 162) —an association which is repeated elsewhere at Foothills Abstract sites - and propose initiation rituals taking place at a bear site with adjacent prints on the lower Musselshell River ([37], p. 173). Again from Australia, Tresize mentions encountering "deliberately placed" stencils at significant Cape York sites - one of them purportedly displaying the hand stencils of seven guerrilla warriors following the line of a repainted snake in a sorcery composition aimed at a black police trooper ([101], p. 16). Superimpositions can be layered in the opposite way to these examples of stencil over figure, i.e., figure over stencils, and may indicate random association. On the other hand Clottes and Courtin note Cosquer hand stencils (placed on a difficult-to-access surface) over which was engraved a "wounded" horse some thousands of years later ([22], p. 73). Since the stencils in question qualify as "gestural language" possibles, and the motif "intersection" might well have been deliberate, the hypothesis must be entertained that such symbols were readable over a long period of time. 
Figure 15. Superimposed hand, Charcamata, Santa Cruz, Argentina.

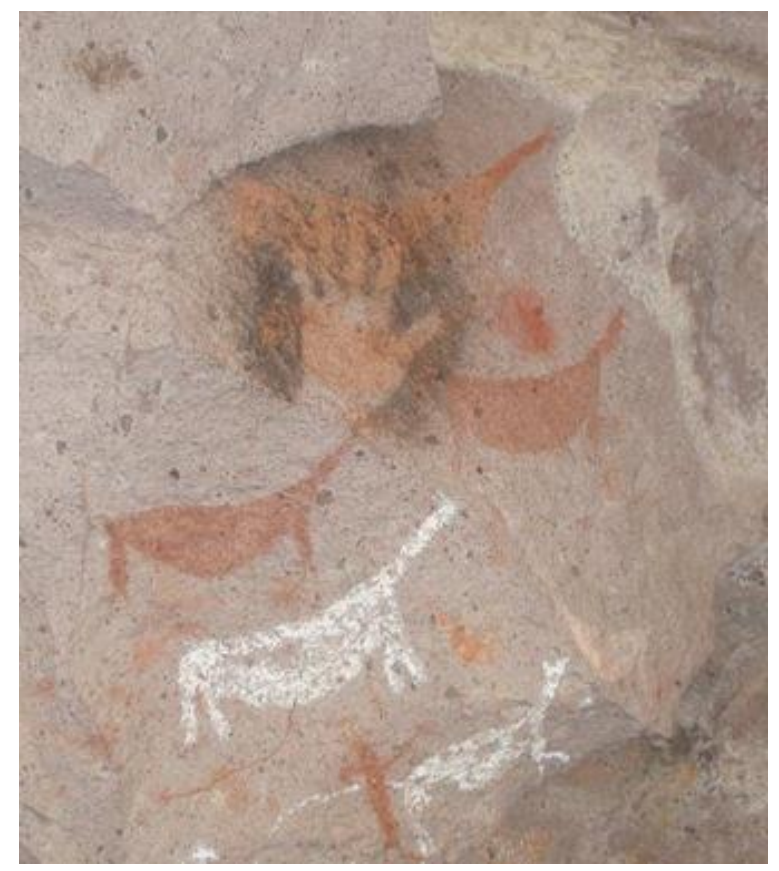

Figure 16. Associated images, Cueva de las Manos, Santa Cruz, Argentina.

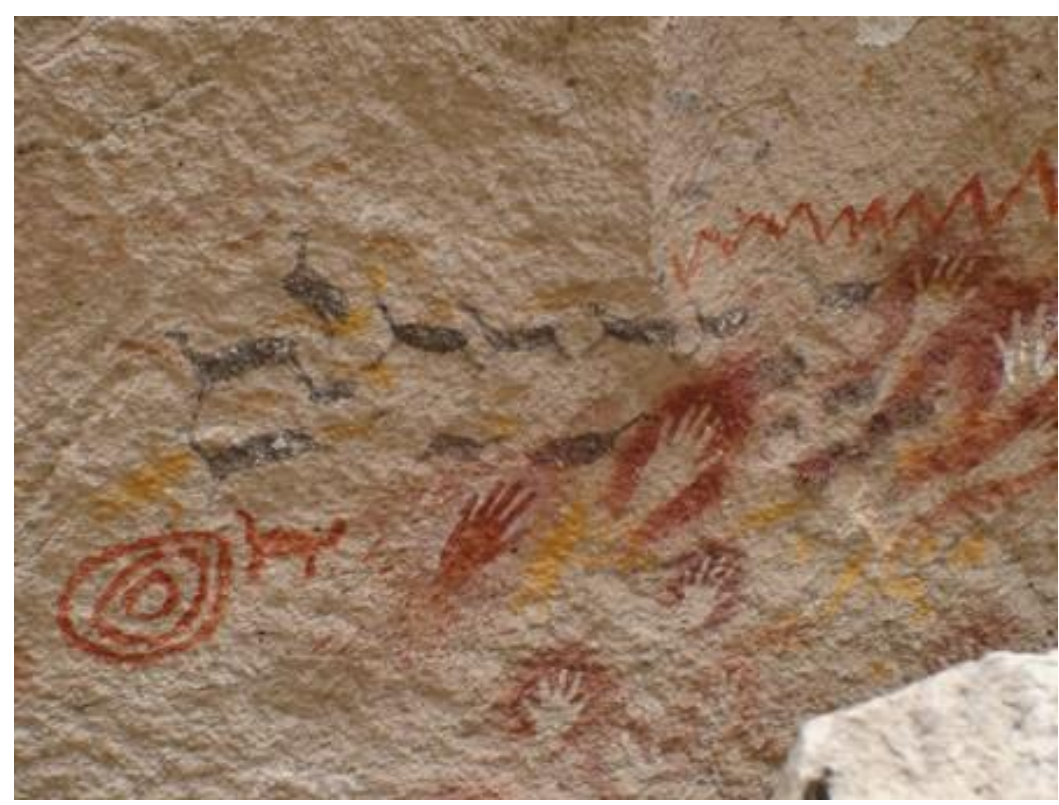

Importantly, the way stencils are associated with one another can be an indicator of probable symbolic meaning. From Australia, this Mt Borradaile ceiling panel (Figure 17) suggests more than an exercise in patterning for its own sake, since both complete and incomplete stencils are present in a line-up which, if read in the direction the hands are pointing, culminates in a fanning out of stencils in varied array. On the grounds of the repetition of the same "clenched or missing forefinger", Roberts and Parker ([27], p. 31) postulate a single stenciler, which could well be the case, as the dimensions of the complete hands appear to match those of the more frequent incompletes. Bouissac argues that if single individual authorship could be postulated for a set of hand images the notion of a sign system at work "would be considerably reinforced" ([102], p. 93). 
Figure 17. Ceiling panel, Mt Borradaile, Arnhem Land, Australia.

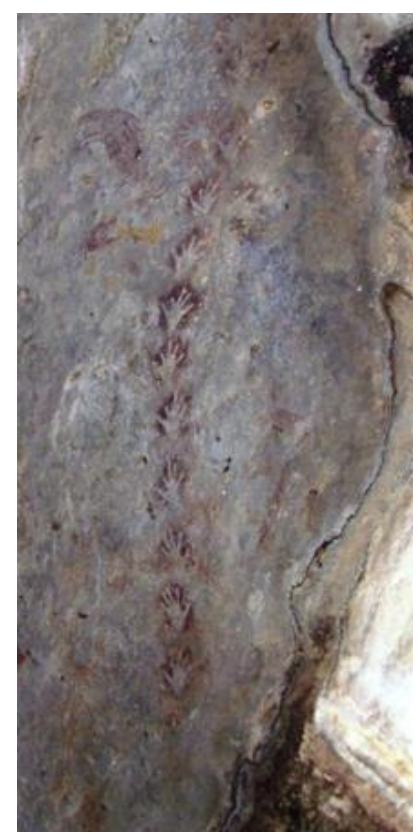

It is interesting to find a record by Keyser and Klassen of the occurrence of "stylized" hands (sometimes with digital oddities) as well as feet, described as "simulated prints rather than the outline of a real handprint or footprint", in the Plains Indian Pecked Abstract Tradition, where they occur in numbers in association with geometric or maze motifs ([37], pp. 142-143). In view of Walsh's "composites", might this suggest a coded symbolic meaning? At times associated Foothills Abstract tradition "hands" with unusual features are interpreted as shamanic "shape-shifters" as in the case of a painted image equally suggestive of a human hand or bear paw ([37], pp. 169-170). As I have already remarked in my discussion of decorated and patterned hands, the more remote a hand image is from direct register of an action, the less it bears on my present concerns. As soon as imagery becomes "simulated", i.e., derivatively mimetic or, alternatively, time-consuming, as is the case with pecked images, it ceases to manifest the immediate trace-quality of prints and stencils whose forms, like animal tracks, retain pictorial memory of an act. This, as we shall see, will disqualify images which in effect "quote" stencil and print impressions from my proposed category.

\section{The Case for a Special Category}

Where, then, does this clearing of the ground get us in terms of a case for a special category for hand stencils and prints? To answer this question we need to look more closely at what a hand stencil is, i.e., how it is to be characterized for purposes of categorization. So far it is clear that stencils and prints express something individual, both as a record of a particular act — and this is a point yet to be fully elaborated - and as testimony to a particular human identity. Though in practice these are not separable, we can distinguish them, the one referring to an individual event, the other to an individual identity specifiable via cultural information. Once the notion of a particular "act" has been elaborated, we can refer to these as the stencil's or print's "act-identity" and its "author-identity"-always bearing in mind that the two work in tandem. It is also important to understand that the present argument is more concerned with the first, though it cannot avoid reference to the second. What about issues of 
"decorated", "patterned" and "gestural language" hands canvassed above? We have seen how decorated stencils of the Arnhem Land variety, while retaining the canonical form of hands, seek to obliterate the distinctive features which enable them to be read as belonging to an author. Following decoration, such hands require a coming into play of cultural memory for recognition of ownership: I will remember that I decorated the stencil made by my relative who has died, but his autograph no longer remains. Patterned prints are like decorated stencils to the extent that they distract from individual authorship, i.e., they are a departure from straightforward facsimile, while their canonical form remains that of hands. So-called "mutilated hands", or transposed gestural language stencils, are readable both as human hands and as exhibiting individuality: witness the Mt Borradaile example where Roberts and Parker ([27], p. 31) discerned a single author in a line-up of such stencils - a proposition measurement might help verify. We also found that cultural variation in such attributes as placement, size and pigment use will not affect hand readability, either at the level of canonical form or of individuality. Again, it helps to think of this individuality as both the record of an event, and authorship, the record of the person responsible for it. Any picture is referable back to the activity of its making and to a particular maker. However, stencils and prints, as (inevitably) assumed from the start of this article, are not pictures of hands. Their individual quality is of a special kind. This is what now needs to be gradually investigated.

If we consider canonical form alone, there is no difference between a hand mark and any other readable image: I read a hand stencil as a hand, and a bison image as a bison, a kangaroo as a kangaroo, a bear as a bear. On the further question of particular identification: clearly, I read Stubbs' painting Lord Grosvenor's Arabian Stallion with a Groom, c. 1765 as a picture of both a horse and a particular horse (Figure 18).

Figure 18. George Stubbs, British (1724-1806). Lord Grosvenor's Arabian Stallion with a Groom, c. 1765 . Oil on canvas. $99.3 \times 83.5$ cm. Kimbell Art Museum, Fort Worth.

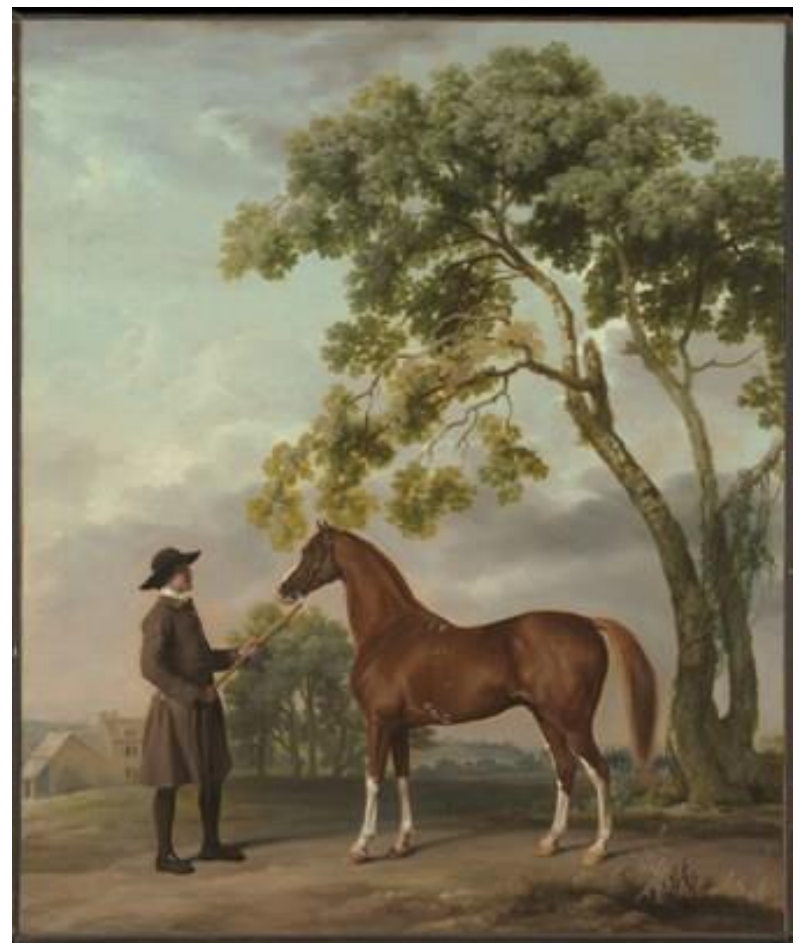


However, reading a hand stencil or print as that of a particular person is not the same thing as identifying a particular Stubbs horse. The particularity of the former has a direct quality, which makes it quite different from the latter. The difference is certainly tied to what rock art researchers are in the habit of describing as the "signature" quality of a stencil or print, viz. those features like finger width and length which cue individual identity. At the same time, the idea of a "signature" may be understood in various ways, not all of them helpful. I shall argue that the hand mark as belonging to a particular individual does indeed qualify it as belonging to a special category of images, but that this needs to be understood in a way that goes considerably beyond the usual idea of an autograph. Let us begin, though, by examining received versions of the proposition that hand stencils and prints amount to "signatures".

\section{1. "Signatures"}

The term "signature" is frequently encountered in rock art studies of hand marks, not necessarily with backup from ethnography or with theoretical questioning. When ethnography is taken into account, particular sources are not necessarily cited. Grant makes the general comment that "modern Pueblo Indians consider the handprint as a kind of signature", supporting his observation with a contemporary example (a plasterer marking his finished work) and an appeal to discoveries of Mayan handprints on pre-Columbian masonry ([69], p. 168). Obviously, it is in those places where there has been a continuation of the practice of hand-marking that ethnographic insights can be sought. Australia, for example, is a privileged zone of maintained stenciling activity. Roberts and Parker [27], who appeal to the notion of signature while writing about rock art at Mt Borradaile in Arnhem Land, are probably relying for their interpretation of the purpose of hand prints and stencils on Forge [103] who in turn cites Taçon-whose own source is traditional owner of Deaf Adder Gorge sites in Arnhem Land, Bill Neidjie ([66], pp. 137-138). Or, alternatively, their source is Bill Neidjie through Mt Borradaile's campsite manager Max Davidson ([27], p. 4). Whatever the case, they are confident that stencils and prints are "signatures; the brand of a particular individual who may have had special associations with the particular area" ([27], p. 30). It is "signature" understood in this sense that I have termed "author-identity".

Often the authority for assertions of individual inscription will be Herbert Basedow's report in The Australian Aboriginal (1925) of the stencils, or "hand shadows", of the Worora peoples of the Kimberley. Basedow's claim was that it is "beyond dispute" that Aboriginal people "possess the faculty of being able to recognize the hand-marks of their relatives and tribesmen, even though they may not have been present when they were made" ([41], pp. 321-322). The naming of stencils as "shadows" ("wongili"), so evocative of individual ownership, is also recorded by Peterson ([104], p. 16) writing about the Murngin of north-east Arnhem Land. In the context of delineating an Arnhem Land practice, subsequently backed up by ethnography from the region, Basedow (1935) once again brought into focus the hand stencil as a "record of individuality":

It is the belief of a native of the north-west that the spirits of departed tribes-people desire to be revered by those nearest to them; and for that reason they keep a tally of their visits made to the sepulchral caves. By placing the imprint of his hand upon the wall, the native leaves evidence of 
his call... Each hand-mark can be recognized, not only by the person who made it but by every member of the tribe, with wonderful precision and reliability.

Basedow further remarked that this capacity for precise recognition should not surprise us in connection with people expert in tracking, pointing out that, in addition to hands, stencils are sometimes made of "the visitor's feet" ([90], pp. 238-239): in other words, feet too can function as signature. Foot-stenciling, although rarely occurring in the rock art record, is not unique to Australia: it has, for example, been recorded in the Sahara at Wadi Sora ([87], p. 29) and in the last to be humanly occupied territory of Patagonia ([39], p. 29). Peterson lists both hand and foot stencils among the ways the Murngin men of north-east Arnhem Land leave "evidence of their presence in a particular place" ([104], p. 16). In his 1925 book Basedow adds stencils of "private belongings" (emphasis mine) to foot stencils, raising the possibility that a sense of personal inscription can also extend to objects which might be regarded as extensions of the self ([41], pp. 321-322). The previously mentioned stenciling of baby's feet might be said to satisfy this requirement, on the grounds of intimate relationship: an infant is not independent of its parent (Figure 19). Flood notes a similar image of baby's feet from Cape York, Australia ([105], p. 412).

Figure 19. Baby's feet stencils, Mudgee, New South Wales, Australia.

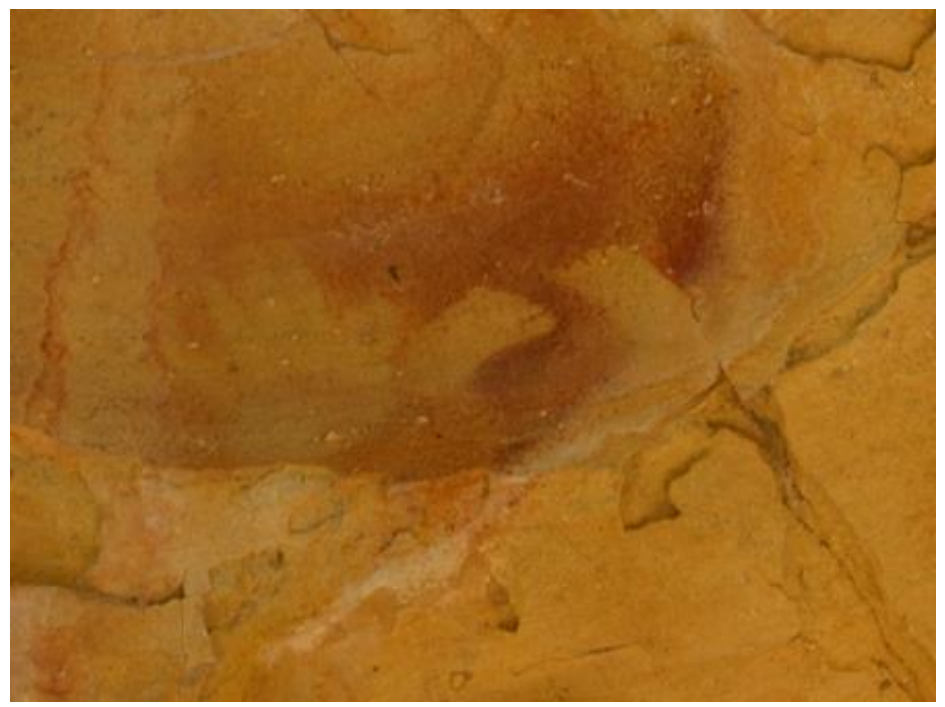

When Moore addressed the question of what he described as "an almost total ignorance of the rationale and significance" of hand stencils, he offered, as a summary of his research of the Australian published record, seven categories of their identified use: (1) "individual signature"/marking a visit; (2) memorialization; (3) address to ancestor spirits; (4) communication with others; (5) historical record; (6) symbolic inscription of myth; (7) invocation of sorcery ([97], p. 318, p. 322). From a global standpoint Bahn similarly prioritized signature: "they could be signatures, property marks, memorials, love magic, a wish to leave a mark in some sacred place, a sign of caring about or being responsible for a site, a record of growth, or a personal marker - 'I was here"” ([73], p. 115). For Tresize, hand stencils at Cape York are "mankind's signature" ([42], frontispiece), but they also serve the function of individual inscription: "Hand and foot stencils they [Aborigines] regarded as signatures" ([81], p. 14). 
The "ownership" or recognizability of stencils has had relevance in the Australian Aboriginal land rights context. Layton, who worked on the Cox River (Alawa/Ngandji) Land Claim between 1979 and 1981 ([106], p. 238), witnessed Clara Tonson's identification of hand stencils at a Gulf country site, including her own, and those made by made people she knew in commemoration of victims of colonial violence ([25], pp. 75-76) — thus attesting to their function as autographs.

Unfortunately, people are liable to read the notion of a hand stencil as a signature very narrowly and reductively: something like the "I was here" idea. The assumption is that, since hands carry visible traces of personal identity, they amount to nothing more than an autograph. However, with hand stencils (and prints) we are not just reading identity cues. Hand marks are already more than a signature of the kind we put on a check or other document. In this sense Bouissac is right when, investigating the part it might have had in the emergence of symbolic systems, he rejects an appeal to restricted "“deictic' meaning" of the "II am so and so, and I was here"” variety ([102], pp. 91-92). At the same time, we cannot simply dismiss the hand mark's quality of personal immediacy. Rather we need to reinterpret, and deepen our understanding of, this quality as something over and above mere "signature". In this connection it is my aim to begin by proposing a universally accessible primary meaning relating to the biological source of hand images, viz. their issuance from the motions of exploratory/performatory bodies.

\subsection{The "Ecological Self"}

Exchanges between philosophers and cognitive scientists about notions of "ecological self-awareness" [107,108] or the "ecological self" [109], the "specification of the self as a place" [107], awareness of "self-agency" and "body-ownership" ([93,110,111], and the role of proprioception (awareness of the position of and forces within different parts of the body) in self-recognition [112], suggest a new approach to stencils and handprints. Both positives and negatives should be seen as marks recording acts of self-recognition in relation to the environment, self-recognition in the sense of an awareness that I am doing this, i.e., having this effect on the world. The fact that such marks remain as traces of an individual act endows them with a special status, one which derives from their visually-readable register of their makers' embodied and environed life. This is what I wish to focus on at this point in the argument: the stencil/print not simply as a record of identity or personal presence ("I am X" or "X was here"), i.e., the "author-identity" of the image, but the image as the record of an individual action or event. We recall that, while stencils and prints do not depict hands, they have the "canonical form" $[92,113]$ of hands, thus allowing them to be read as hands, not merely human hands in general but the hands of particular people. However, this is not the whole story, and perhaps not even the critical point. What makes the stencil/print unique as an image? I have already alluded to this by referring to its "immediacy", its providing a "direct" record of something. This directness is tied to the image as a trace of the action that produced it. A stencil differs from a depiction, say the Mona Lisa, both as a record of the event of its making and as a record of the identity of its maker. To begin with, it records not various events but a single event. Therefore, it has the immediacy of that single act. Moreover, it is self-referential in a way the Mona Lisa is not. What of the self-portrait by Leonardo (the famous one in Turin)? That would be a picture of, not a direct trace of the author. The stencil is critically a trace, direct in that it is a trace of an (authored) event, and peculiarly of the event 
as event. All pictures refer back to the act that produced them, but not in this way. What is unique about stencils is the fact of iconicity intimately one with its making, the act that endures as a trace. However, what brings such uniqueness into play? What exactly is involved when I leave an image of my hand on a rock surface? It might be asked: do we need to go beyond our quotidian appreciation of ourselves in the world to understand something as obvious as a visual autograph? The fact is that there is a growing literature on the subject of human body awareness that may help to deepen this understanding, ultimately providing evidence for a link between 'perception of one's own and others' bodies" ([114], p. 4). If we are interested in the way hand marks - so frequent in rock art, so straightforward in their manufacture and so transparent in their iconic readability - function both to specify self-recognition in the act of marking (as "act-identity" and not merely "author-identity") and, in due course, for person-to-person communication, cognitive psychology and neuroscience are promising fields. I shall begin with an examination of the act of making a stencil or print.

Logically, this means we first need to look at the "ecological self" engaged in the spaces we occupy in a specific environment by attending to the manner in which we make use of its affordances (to employ Gibson's word). These will be affordances for shelter and nourishment, for facilitated locomotion and, relevant for the present context, occasions for self-reflection and, concomitantly, communication. When we approach the topic of hand-marking from the perspective of what Shontz chooses to call the "embedded self" ([115], p. 94), the human body itself comes into focus as a the sole tool employed in an interaction with the environment - a hand on the rock wall, minerals ejected from the mouth - to produce a mark which affords an opportunity for self-recognition. At this point, we, as rock art researchers, are compelled to engage in a new conversation with cognitive psychologists about the way a perceiving self perceives itself. From this point of view, our preoccupation will be the emergence of a specified self, which has its origins in "an awareness of where we are, what we are doing, and what we have done" ([109], p. 9).

At the rock face, palm to surface, I come metaphorically, face-to-face (literally hand-to-hand) with myself. Self-recognition comes through the tool I have employed, my body, which is a conduit, in the language of cognitive science, of both "proprioceptive" and "exteroceptive" information. The information which specifies me to myself in the action of stenciling depends on what is coperceived proporioceptively from changes of posture as I lift my arm, place my hand against the rock wall and spit from the mouth, and exteroceptively as I pick up sensory input from the movements of my hand over the texture and contour of an affordant surface ([2], pp. 112-113; [116], p. 154; [117], p. 53). Visual feedback also figures importantly in the self-specifying loop. Moreover, my access to visual information - delimited by my trajectory through the world - confers on me an ecological "field of view", thus allowing me to gauge my position in relation to other things within my range ([108], p. 112).

There is also information for a sense of agency ("I am doing this") and a sense of body ownership ("this is my arm and hand"), aspects of self-awareness, which normally work together but may, in some situations, function independently. Such situations are currently under experimental scrutiny by cognitive scientists [93] since the distinction between agency and body ownership was first made by Gallagher [110] in the context of describing a non-conceptual "minimal self". Using the example of my reaching to pick up a glass, Tsakaris et al. define my sense of agency as "the pre-reflective experience or sense that I am the cause or author of the movement" and a sense of ownership as "the pre-reflective experience or sense that I am the subject of the movement", viz. I am the one lifting 
the glass ([93], p. 646). In an adaptation of the famous "Rubber Hand Illusion", Kalchert and Ehrsson [118] have shown that by modifying experimental conditions a sense of agency and a sense of ownership can be suspended separately: "our results demonstrate that the feelings of ownership and agency can be dissociated, suggesting that these sensations represent independent processes of the human brain". Neural substrates have been sought for both senses, with some evidence (subject to further interrogation) of linkage to different areas of the sensory motor system ([118], p. 9, p. 12). What is important for the present argument is the perspective a sense of agency and a sense of body ownership_both in their normal mode of working together (with contributing proprioceptive information coming from muscles, joints and skin [119] in addition to visual input) and in situations of possible separate functioning - can bring to print marking and stenciling. The human organism being what it is, viz. a locus of self-perceived, self-specifying activity in the world (the body locates its position in space), we can be confident that makers of hand stencils and prints possess an awareness of themselves in hand-marking - as they would in any activity. So what is special in this particular activity that requires further discussion?

Beyond the act through which I know my body as my own, its agency and its influence, there is the external image produced by hand-marking. As a trace of the original act this image, as argued above, is also self-specifying. A trace is precisely the register of an actual event and, in the case of hand-marking, an idiosyncratic one linked to me as agent, viz. to me as a particular person. As such, it is so direct, singular and self-evident that this in itself makes it distinctive when compared to other images. Iconic in a very special way, hand traces- "shadows" to Kimberley and Arnhem Land Aboriginal groups - are unlike any other kind of representation and demand more analysis from a genre standpoint than they have received to date. Except for the "pathology/mutilation versus gestural language" debate, researchers have tended to concentrate on the details of particular sites rather than pursuing avenues which might throw light on hand marking as a global phenomenon. One avenue is surely the cognitive psychology one which introduces relevant notions of agency and body ownership. In this context, and focusing — at this point — on the external hand image, we might attribute more than metaphoric significance to the Aboriginal characterization of hand traces as "shadows". Although interest in the shadow has been marginal to other interests in cognitive psychology, attention has recently been paid to the way our shadows are linked to our body awareness. One question relating to the phenomenon of the incorporated fake limb (cf. the Rubber Hand Illusion)—where ownership and agency are separated - centers on the possibility of the mapping of shadows as body parts. Visual experiments have indicated that "the brain automatically codes shadows cast by the body as strictly related to the body itself" ([120], p. 79). Might not this be true of hand traces? We can speculate that hand traces might, like our shadows, "bind" us to what is external to our bodies and extend our sense of ownership of ourselves ([121], pp. 20-23), an intriguing idea which can only apply to representations of body parts, and not to cupules, geometrics or non-anthropomorphic figural images. This in itself suggests a uniqueness in hand traces, which deserves investigation.

So what is unique is not only the act of stenciling which generates self-recognition but the externalization of the act in the form of a replica or trace of it. Assuming with Gibson that perception is always coperception of oneself and the world allows us to posit a basic self-specification which provides the ground for other forms of self-consciousness. From an evolutionary standpoint, this is where the story begins, with an organism's receptivity to self-specifying information in a relationship 
with an environmental exterior, which is biologically internalized and, conversely, a biology which is "coupled" to that exterior [117]. Insofar as hand marks capture the ecological self in action they are to be viewed as autoregistered biological events which bind the maker to the made, action to its trace.

In this context we can agree with Forge's comment, made at the inaugural AURA Congress in Darwin (1988), to the effect that hand stencils "might form a genuine separate category" in rock art ([103], p. 40) — an observation which Rosenfeld [122], who endorses Forge's general argument, extends to hand prints. Unfortunately, Forge, with a glance towards Lévy-Strauss's raw/cooked binary, reads the process as "a transfer directly from nature" ([103], p. 40, my italics), from which he draws a series of conclusions which it is hard to take seriously. Hands in rock art, he thinks, belong to "nature" and not "culture", to the individual and not the social sphere, to mechanical reproduction and not to "art". A lot of this hinges on a highly dubious interpretation of Taçon's account of the overpainting of stencils of the dead in Arnhem Land so as to obliterate individual identity [66]. In which context, the original stencil comes under the heading of "nature" and the overpainting under that of "culture". This does not make much sense: clearly the entire stenciling/printing process is culturally driven, highly socialized (despite its individualized reference) and its outcome is as much "art" as any other image. It is true that hand marks, like trackable spoors, possess a primary biological meaning which is prior to culture. Indeed it is just this primary readability which makes them entirely useable in cultural terms. But the primacy of the biological needs to be thought through in terms of the "ecological self". It is along these lines that $I$ have been putting the case for the distinctiveness of hand marks on the basis of (given that the human body is the tool) unmediated register of an individual act (with individual authorship) via externalized trace, i.e., the mark itself.

While the hand as an instrument is used in the making of all rock art-whether directly, as is the case with finger flutings, or indirectly, if a tool is involved-stencils and prints uniquely represent the hand in self-reflexive mode. As Clegg rightly noted, we are not investigating a mimetic representation [123]. We are dealing with an image, which, while akin to the mimetic, is more potent in the information it carries, viz. information about a spatio-temporal act, which leaves a replica of itself. I shall be describing this replica as a proprio-performative image. For the maker, the stencil/print affords an opportunity to reengage with the original act of marking. For another comer, it prompts recognition of such an act through the receiver's bodily awareness of possessing the capacity for such an act. Through this person-to-person exchange of information - postural, structural, kinetic - possibilities for communication are opened up, including those expressed in sign systems. A hand mark is more than an inert mark, and to see a chronicle of the ecological self in it is itself not a trivial or mean thing. However, what if even replicating a specifically individual biological identity is only the beginning of the story? It might just be the case that hand marks are the sine qua non of visuographic (as opposed to spoken) discourse. Nevertheless, there is ground to cover before such claims can be made.

\subsection{The Rock Surface as Rudimentary Mirror}

Having discussed the agent, the act and the image or trace, I now turn to the reception of the image by any reader, including in the first instance the author of the hand mark. Once disengaged from the performatory act of hand-marking, the maker is indeed in the position of any other observer. For the maker, a sense of continuity in the event is in part delivered by a perception of cause and effect, but 
more than this is needed for recognition of the hand image as one's own. This comes about through "kinaesthetic visual matching" (KVM), in which what I am doing is related to a visual image of that action ([124], pp. 88-90). The proposition that it is an action, and not merely a static image, which is captured in a hand mark will be further examined when we discuss the notion of "performative" images. For the time being, I shall appeal to the perceptual option of a left-hand/right-hand, dorsal-to-frontal switch (or vice versa) that flows from the fact that a trace is a replica of my hand, viz. its canonical image. This option in itself permits a mirror analogy to be used with confidence in the present context. However, as we shall see, the case for regarding a stenciled or printed hand-mark as a mirrored image is stronger than these comments suggest.

Let us assume, then, that the rock surface on which I am stenciling/printing offers the affordance of a rudimentary mirror. Since Gallop's 1970 mirror recognition test with chimpanzees (the "mark test"), subsequently augmented by studies involving videotapes, photographs and shadows, the capacity for self-recognition in a mirror has been tested in primates and other animals, with great apes qualifying as possessing it [125]. Recently Rochat and Zahavi [126], revisiting Merleau-Ponty [127], have come at mirror recognition from another angle. Their aim has been to redirect attention to the mirror's capacity to project the self as other. For a subject to "recognize the specular image as its own is for it to become a spectator of itself". Again: "when seeing myself in the mirror, I am seeing myself as others see me. I am confronted with the appearance I present to others. In fact, not only am I seeing myself as others see me, I am also seeing myself as if I was an other" ([126], p. 209; see also [121], p. 23). Confirmation of this possibility comes from mirror-recognition experiments with monkeys, where results indicate a social response to mirrors rather than a self-absorbed one involving self-directed behaviors. In other words, monkeys respond to images of themselves as conspecifics, i.e., other monkeys [128]. Since this is true for many species, it is unlikely that humans do not possess this trait. Rather it suggests that the primate self-recognition response requires a delayed, non-spontaneous spatial readjustment. In fact Anderson, who set up monkey mirror tests, points out that other experimental results show that "self-recognizing primates (i.e., great apes and humans) also pass through a phase of social responding to their reflections before self-recognition emerges and social tendencies drop out" ([128], p. 318).

As maker, I "own" my hand and acknowledge its agency in the moment of self-recognition. However, as I am confronted with the trace of my action, another set of responses comes into play and these relate to the othering factor inherent in the mirror. To elaborate on this I need to turn to the notion of "representational momentum" (RM) [129] because studies of perceived movement in static images can bring a new perspective to the understanding of a viewer's reception of trace hand images in rock art. It is within their framework that we gather additional support for the mirror analogy drawn above, as in the light of RM it is possible to argue that the hand (and sometimes the arm and hand) traced in hand-marking will be perceived by a viewer as a forwardly moving, i.e., "performative", image. This means that the rock surface as representational canvas is not limited to "frozen" imagery. The hand in the rock art mirror can be said to move. However, before examining the role of RM in bringing about a perception of hand motion through the trace of a hand doing something, performing an action, it is necessary to look at what hand marks have in common with other performative images. 


\subsection{Performative Images}

Relating his category to Austin's and Searle's Speech Act theory_-"a performative statement is one which is not merely about something; rather it does what it says" ([130], p. 151) - Livio Dobrez has defined performative images in a number of contexts [131,132]. In the process, he has put the case for "Performatives" as a "perceptual universal" ([130], p. 149). The type image put forward is a Wandjina in Australia or a Barrier Canyon anthropomorph in America, figures that confront the viewer as if in direct address (Figure 20).

Figure 20. "Looming” Barrier Canyon performative figures, Utah, USA.

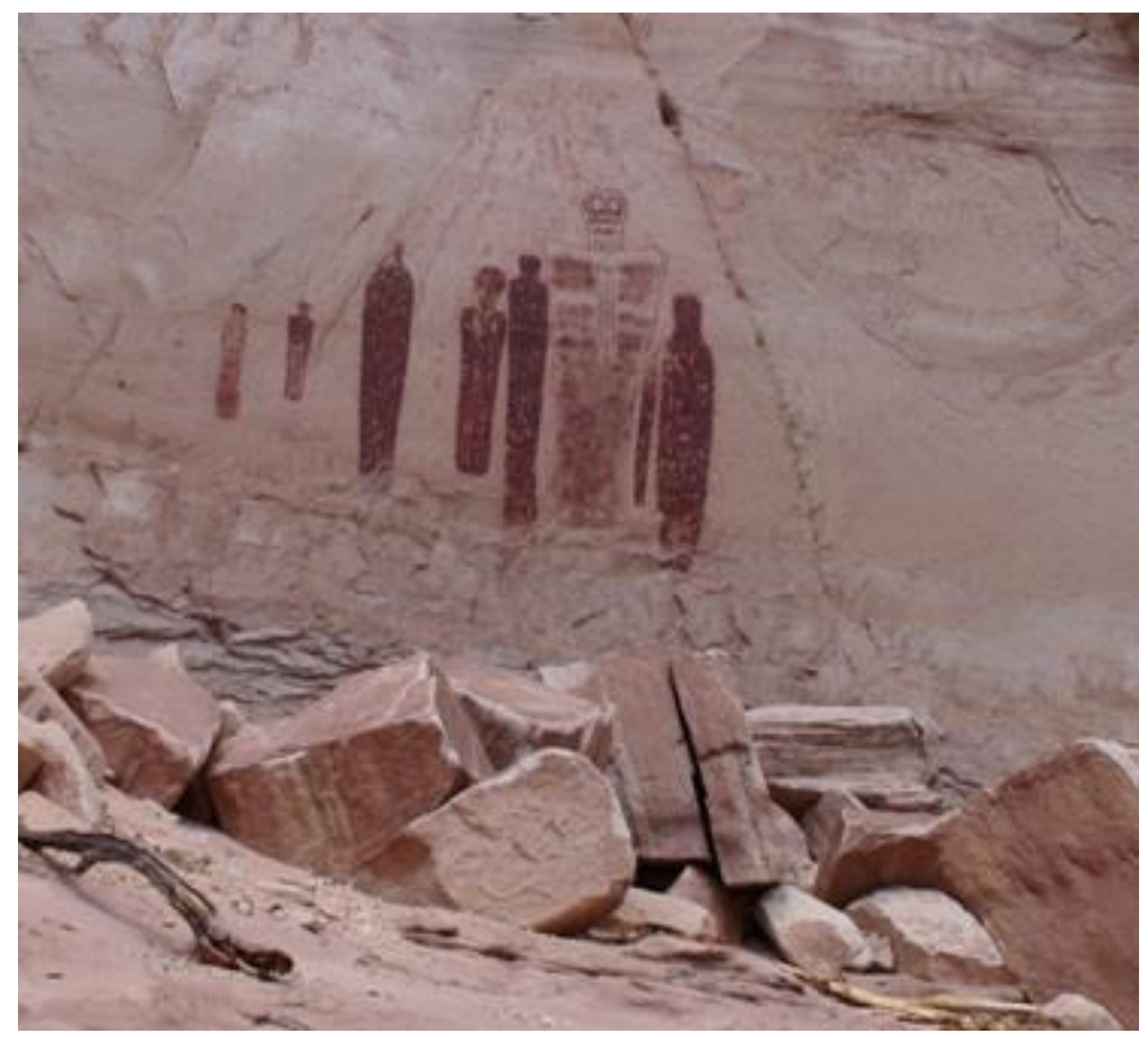

The three meter high Milbrodale Baiame (Figure 14), with piercing eyes and arms outstretched to a width of more than five meters, belongs to this category. Such frontal representations stand in contrast to profile figures, which constitute "scenes" in rock art, like the "dancing" Gwions of the Kimberley, Australia, or figures said to be engaged in battle at Injasuthi, South Africa. These belong to the category of "Narrative" images. In 2012 Dobrez added hand stencils to the performative list, arguing that "a stencilled hand is read as "arresting", "commanding attention": "Like full-frontal figures, especially including prominent eyes, it as we say, "stops you short"” ([130], p. 156). This "arresting" is understood as a perceptual/depictive universal - to which the culture-specific sign "stop" may be attached. One or both of these may be intended by Banggal, a custodian of Ngarinyin law from the Kimberley, Australia, who "sings" stencils in this fashion: 


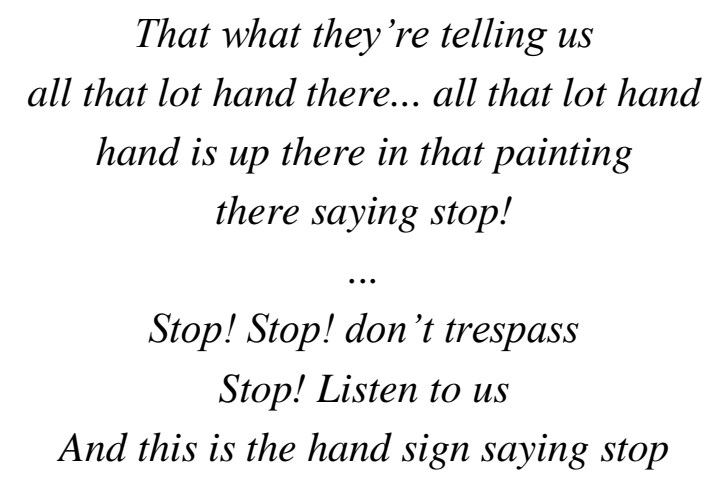

([133], pp. 38-42; see also, p. 304)

Identifying possible neural substrates for reception of performative images, Livio Dobrez has pointed to face-selectivity located in the inferotemporal Fusiform Face Area, which also seems to include eyes and hand-specific areas ([130], pp. 158-159). More recently (see this issue of Arts) he has pinpointed areas in the superior temporal (V5/MT) related to another significant quality of such images, viz. their dynamism.

While contrasted to dynamic narrative images constituting "scenes", performative images are also capable of suggesting the idea of something happening, but in this case, it is a something happening to me, rather than a passively observed event. As Dobrez describes such images, they are to be characterized by their "looming" effect: the figure appears to approach, entering the viewer's actual space, and this is what will be argued here, viz. that hand marks are confrontational in such a manner as to suggest encroachment on the viewer's personal space. In order to grasp this it is once again necessary to focus on the option of a perceptual switch. In that a trace (through the position of the wrist in relation to palm and fingers) retains indications of the angle from which the rock surface was originally approached, it will allow the position and action of its maker to continue to be "felt" in a bodily way. Once the perceptual reversal comes into play, however, these (slight) directional indications prompt the sense of a palm facing towards the viewer, that is, suggesting movement away from rather than towards the surface. This movement too will be registered in a bodily way by the observer. Considering a hand trace from the standpoint of perceived movement immediately invites recourse to a mirror neuron explanation for the reception of hand traces as performative. Citing Urgesi et al. [134], Watson drew attention to the involvement of mirror neurons in "the perception of pictures" ([135], p. 79). In the present context, a role for mirror neurons suggests itself as a logical extension of the performative thesis. However, before examining the possible relevance of mirror neurons to this discussion it is first necessary to ask: how can a hand trace be seen to move?

\subsection{The Looming Effect and Representational Momentum}

At IFRAO 2013 in Albuquerque, New Mexico, Livio Dobrez first introduced the notion of representational momentum $(\mathrm{RM})$ into the discussion of performative images, but without looking at its possible application in the case of hand marks - which is what I propose to do here. (At the same time, I refer the reader to Dobrez's extended treatment of the subject of RM in this issue of Arts.) As a starting point in a discussion of RM in relation to hand stencils and prints we need to take on board the tested notion that when we view an object depicted in motion we register that motion in a way that is measurable. 
Cognitive psychologists have found this to be the case. Freyd originally proposed that "photographs that capture or 'freeze' some object in the process of motion might induce a mental representation of movement" and set up tests accordingly [136]. Her results supported the hypothesis, leading her to propose the idea of "momentum" in a mental representation in a joint article with Finke, suggesting evolutionary advantage in the detection of movement, which anticipates continuance [129]. Especially relevant for hand marks are the experiments devised by Kelly and Freyd [137] to test size transformations (both increases and decreases under "'grow' and 'shrink' conditions") in relation to the inducement of the momentum effect. These last experiments also involved static images and indicated RM for size change, which was inevitably viewed not as size change but as representing "a perspective transformation of an object approaching towards or receding from the observer in depth". The subjects of these experiments described an object as either "looming or retreating from them in depth" ([137], pp. 384-388). In spite of these results, Kelly and Freyd expressed a caveat: that the momentum effect might be a function of size change alone and not due to perception of an object of constant size approaching or receding. To satisfy themselves they carried out two further experiments, with results tending to confirm the original assumption ([137], pp. 392-393). It must be stressed, though, that whether the looming effect is produced by the size of the object or by internalized momentum is not significant for the present argument, because what concerns me is the fact of perceived and (in the Freyd experiments) measured displacement, i.e., movement, however produced. In that context, my interest is less in RM per se than in the phenomenon of looming-which indeed registers as perceived movement in RM experiments. In relation to Livio Dobrez's performative images and to the present discussion of hand marks it is movement towards the viewer - the looming effect - which will preoccupy us. Hand marks frontally approach the viewer who registers a looming effect, as did the subjects in the RM experiments. In other words, the viewer sees the image as performative.

This is the hypothesis I put forward and it is a testable one. Admittedly, RM experiments generally deal with frontoparallel movement rather than movement in depth. With the former, the object is perceived as laterally unstable, so providing a cue for continuance of movement: the object appears to shift in a given direction, left or right. Instability of this sort is not a feature of looming motion, but this does not mean that what looms at the viewer is perceived as stable. Its instability is of a different kind, because it operates in depth: the object appears to be coming closer, i.e., shifting forward, towards the viewer. There is the further point that RM experiments characteristically involve a sequence of images, whereas in the situation of viewing a hand mark we are dealing with a single image. In the experimental situation, as designed by Freyd and others, we require at least two images so as to demonstrate that memory of the first image overshoots the mark, i.e., the second image registers as being in the same position as the first when in fact it has advanced further. This is what demonstrates that we registered the first image as moving. If we remove the second image we have still registered the first image as moving - the only difference being that, in the absence of a second image, the demonstration is experimentally incomplete. On the other hand, in everyday situations such as that of viewing a single hand mark, there is no need to prove that the image registers as moving, in this case as looming. Perceived motion in depth, discussed in terms of RM by Freyd, is prompted by that frontal confrontation characteristic of hand marks. I propose that the phenomenon of looming is an observable fact in the situation of viewing hand marks. At the same time, it is also, as I have said, 
testable along the lines of a Freyd experiment. We could show two successive hand images, the second slightly larger than the first. If observers judged the two as being the same, it would demonstrate that the first had been displaced forward, i.e., towards the observer. Bearing in mind that, in a single hand mark, size, as well as frontality, are liable to trigger the sense of looming, I would add that the hands in question might need to be of a certain size in order to obtain a momentum effect (with child hands possibly attenuating it). It is also possible that, where it is especially marked, the characteristic pigment "halo" around the stenciled hand might enhance the effect. These too are testable propositions.

Interestingly, Freyd's claims for RM have been put to the test in a very different context by Urgesi et al. using transcranial magnetic stimulation (TMS) to record responses to static color photographs of hands measured for perceived movement. This was not in connection with a frontally looming image, but is of special relevance here, because it implicates mirror-neuronal mapping of depicted body movement. The choice of snapshots of hands provided a context for linking the experiment with the work of Rizzolatti and Craighero on observed actions and mirror neurons [134,138]. There is a growing body of literature on the perception of movement perceived in static pictures and the phenomenon is now well established - along with its neural substrate [139-141]. I shall address the subject of a role for mirror neurons in our perception of hand traces. Before doing so I want to touch on an aspect of hand marking which, in connection with mirror-motor mapping, might throw light on that "first" impulse, the $u r$-impulse, to repeat the marking act again and again - thus setting in train a foundational cognitive activity.

Let us allow that, like the "performative" Milbrodale Baiame, hand traces are seen to loom and that they are, as I have been arguing, frontal images seen in a rudimentary "mirror", the rock surface. Together with reflections in water and with shadows, the hand trace becomes a candidate for self-recognition in the mirror. A particularly interesting detail of Anderson's research with monkeys into "mirror-image stimulation" (MIS) has significance here. Anderson's results prompted him to call his paper "The monkey in the mirror: A strange conspecific" [128], and this because responses elicited by the perceived conspecific were at times "more intense" than normal. Rochat and Zahavi aim to put this "strangeness" in the context of the modern concept of "alienation", the notion, borrowed from Merleau-Ponty, that mirrors are in some fashion "unsettling" in that they "exemplify a troubled form of self-knowledge" ([126], p. 209, p. 212). Mirror images are said to possess an "uncanny character" in their "intermingling of self and other", with the consequence that self-knowledge goes hand-in-hand (forgive the pun) with self-alienation. The upshot of such alienation — so the argument goes - has been an association of mirrors with fear and loathing in myths around the world. Against this view I can only suggest that the authors revisit Anderson's experimental results gained from studying monkey responses to MIS. Anderson reports that interacting with a mirror image "can partly compensate for the negative consequences of being reared in the absence of conspecifics" and indeed has a "calming effect" on macaques deprived of a partner ([128], p. 321, p. 323). Since it is unlikely that MIS experiments of this particular kind will be replicated with human subjects, we might take account of this research and refrain from postulating any stock response of the fear and loathing sort while being especially suspicious of Merleau-Ponty's theatrical Hegelian proposition that in the specular image "I am torn from myself" ([126], p. 209).

There might be another way of explaining the perception of self in the mirror-and what we are by analogy looking at here, self in the traced hand-as a particularly intense experience. It has to do in 
the first instance with the looming effect. Something that looms can in itself be overwhelming, like an approaching fist or an oncoming locomotive-favorites of the comic book cover. That said, why would this be more intense when I confront myself as an othered self in the looming posture - through that mirror volte-face previously discussed? This, I suggest, can be explained by mirror neurons, but only if we accept the case for perceived movement in a static image - for the reason that such neurons respond to actions, both transitive and, importantly for the perceived movement of hand marks, intransitive. For mirror neurons to come into play, hand traces must be seen to move. However, where does this line of argument lead in terms of our postulated $u r$-impulse?

\subsection{Mirror Neurons}

Let us hypothesize that hand trace images loom, and therefore, like Urgesi's photographed hands, can be perceived as moving images and, in the light of Freyd's work, as instantiating RM. This puts us in the position of performing a thought experiment relating to mirror neuron activity in observers of such images. First, we need to comprehend what mirror neurons are said to do. Rizzolatti et al. [19] argue that mirror neurons have a role in both imitating and understanding action. Answering their own question "what are the neural bases for action understanding?" they reply that "we understand actions when we map the visual representation of the observed action onto our motor representations of the same action". This they call the "direct-matching hypothesis". Facilitators of an "action observation/execution system" which is postulated for monkeys and humans are precisely specialized visuo-motor ("mirror") neurons ([19], p. 661). It has been demonstrated that in addition to responses elicited when monkeys observe transitive hand-object actions, like grasping or holding, humans also respond to non-goal related actions ([138], p. 175, p. 176, [142]). Foundational mirror neuron studies have mostly involved hand actions. Attention has been given to activities of the mouth, with evidence for an evolutionary derivation of some "communicative gestures" from "ingestive actions". In humans, an "incredibly confusing organization of Broca's area" is postulated, "where phonology, semantics, hand actions, ingestive actions, and syntax are all intermixed in a rather restricted neural space" ([138], p. 171, p. 186). Rizzolatti and Craighero claim "great evolutionary importance" for the mirror neuron system, arguing that "the mirror-neuron system is the system at the basis of imitation in humans" ([138], p. 172). They then proceed to outline the function they regard as prior to imitation, viz. the mediation of an understanding of others operating on the basis of the mirror-neuron system ([138], p. 176). Their further proposal, previously articulated by Rizzolatti and Arbib [20] and supported by others, is that the mirror-neuron system, for the very reason that it facilitates imitative capacity, represents "the neurophysiological mechanism from which language evolved" ([138], p. 183). The origin of speech is seen in communication through gesture, with mirror neurons constituting "the neural basis of a mechanism that creates a direct link between the sender and the message received". On this scenario, imitation took advantage of neural activity in response to mime and non-goal-oriented action (not available to monkeys) to arrive at gestural communication and ultimately the "oro-laryngeal gestures" that constitute speech:

A necessary step for speech evolution was the transfer of gestural meaning, intrinsic to gesture itself, to abstract sound meaning. From this follows a clear neurophysiological prediction: 
Hand/arm and speech gestures must be strictly linked and must, at least in part, share a common neural substrate ([138], pp. 183-184).

As mentioned at the outset of this paper, there is corroborative evidence for this in the activation of an area associated with speech (Broca's area) during human brain imaging experiments designed to localize the mirror system ([19], p. 664; [18]).

At this point, we are in a position to offer an explanation of why seeing oneself as other might be a particularly "intense" experience. Do Rochat and Zahavi's use of words like "strange", "unsettling" and "uncanny" [126] go some distance towards an understanding of the mirror experience as out of the ordinary? Confronting myself as looming - measurable by RM experiments - may in itself unsettle me. Confronting myself as a looming other (who is uncannily myself) will involve something more intense. With postulated involvement of the mirror-neuron system as activated by the observation of movement, I am caught up in a self-agitatory loop as the excitation of my motor cortex not only maps what I see onto existing motor networks implicated in action but connects specifically with my own motor memory of a particular behavior. This means that my mirror neurons not only "resonate" with the perceived movement, but reinforce what is structuring my neural network from an already performed action. Far from thinking of this as an "alienating" experience, we might postulate fascination: an enthrallment prompting the author of a self-referential image to repeat the action, again and again, in self-mimicry. But this behavior also has communicational possibilities, because what allows me to commune with myself, also allows you as my stand-in to map the image of my hand/arm and hand action onto your motor cortex. This also means that, on the "direct-matching hypothesis", you are being primed to repeat the action. Thus, the scene is set for enhanced socialization through a person-to-person exchange based on imitation. Self-imitation and imitation by an other. It is, finally, this inherent property of allowing interpersonal exchange in a dynamic situation of direct address that puts hand stencils and prints in a special category.

\section{What Qualifies as a Proprio-Performative?}

Looking at hand images as performative, i.e., as externalized traces of an "ecological self" which prompt "representational momentum", i.e a looming motion towards the observer on the part of an image registering as other (even to an extent for the maker-as-observer), puts the "signature" aspect of stencils and prints in an entirely new light. Looking at performative hand images from the point of view of mirror-neuronal activity takes the point still further, in a way which might have bearing on the evolution of art and symbolic systems. The subject of our enquiry has been transposed gestures, i.e., gestures that are captured in graphic, quasi-representational form and that lend themselves to communication. These marks, generically recognizable by virtue of their iconicity, and also particularly recognizable as traces of individual hand actions, present a special affordance: they can represent me in my absence. In turn, they can be employed by others in conversation with me. In the communication stakes my autograph mark gives me something to trade. Thus begins an external system of direct address that can liberate author and reader from face-to-face constraints.

Notwithstanding the multiplicity of approaches to hand images possible in rock art research canvassed in the first part of this article, it is important to keep in mind that there is a constant in the way stencils and prints are perceived. Because of the diversity of stencil practice around the world and 
their deep-time lineage, Le Quellec argued that "it is impossible to see in them a univocal sign, a kind of universal symbol which a reading grid might enable one to decipher" ([87], p. 28). While there is obviously truth in the statement, a vital point is being overlooked. The universality of hand marks lies in their primary meaning: that they unfailingly communicate individual presence and that they do so in the perceptual-biological way just outlined. Regardless of complications, they will be read along the lines here proposed.

\subsection{Cultural Conditioning in Hand-Mark Reception}

This is not to assert for a moment that, in the absence of cultural knowledge, hand marks may not be grossly misconstrued. The example I put forward is an Australian version of the kind of culture-shock response, which gave rise to the mutilation/disease theory of digital variation in Europe. It is a piece of lurid 19th century journalism, which describes a white-colonial encounter with a stencil site in central Queensland (cf. Figure 10). On the Walsh-Wright model, the panel, which features bent-finger images, is a likely case of transposed sign language. It can be assumed that, for those proficient in it, these were candid and familiar stencil images relating to events and objects encountered in everyday life, viz. signs drawn from a conventionalized repertoire. "Calipers", giving an account of his site for Melbourne Argus readers of 16 May 1891, responds as follows:

It represented a sea of or lake of fire, and out of that were stretched dusky brown arms, hundreds of them, in every conceivable position, some that almost spoke, the muscles knotted and the hands grasped convulsively; some pointing a weird skinny finger upwards, others clenched as though in the agonies of death [143].

"Calipers" has imposed on the panel the structure of a scene of the kind that might be encountered in Doré (1832-1883), the famous illustrator of Dante, whose work he explicitly invokes for comparison. Habituated to perspectivalism, he ignores what I have been attributing to hand stencils, viz. their performative, direct-address function, although he does report of some stencils that they "almost spoke". For him, the hand images are so culturally alien as to require a malefic explanation relating to some kind of spiritual and bodily deformity. On the face of it, having no key to the symbolic code, he sees only a gruesome scene from the Inferno. What is inescapable, however, is his sense of felt movement, of resonance with pictures which in some fashion re-present action. His mirror neuron system has been activated in no uncertain terms, and he feels that he is being addressed. What is more he recognizes through the hand images a human presence. It might also be the case that Calipers is reading not only the primary autograph meaning of the hands and their gestural address, but the vigor and intensity of their execution: see Freedberg and Gallese on the subject of "embodied simulation" for aesthetic responses to gestural traces of brushmarks, tears, cuts, and the like [144,145]. While the Calipers example certainly illustrates the way cultural conditioning can miscue reception, it equally shows that we possess a perceptual apparatus, which operates universally, viz. across cultures: I recognize a conspecific when I meet her.

Such recognition explains why cultural education comes relatively easily. In my own Canberra suburb the hand stencils of schoolchildren (under the supervision of local indigenous artist Lewis Langton) have been incorporated into a mural (Figure 21). Here the visual allusion to indigenous sites 
recording presence is readable by a now acculturated population. Minus the distraction of novelty, it is to any comer a transparent record of juvenile presence.

Figure 21. Hands mural at Mt Majura Primary School, Australian Capital Territory.

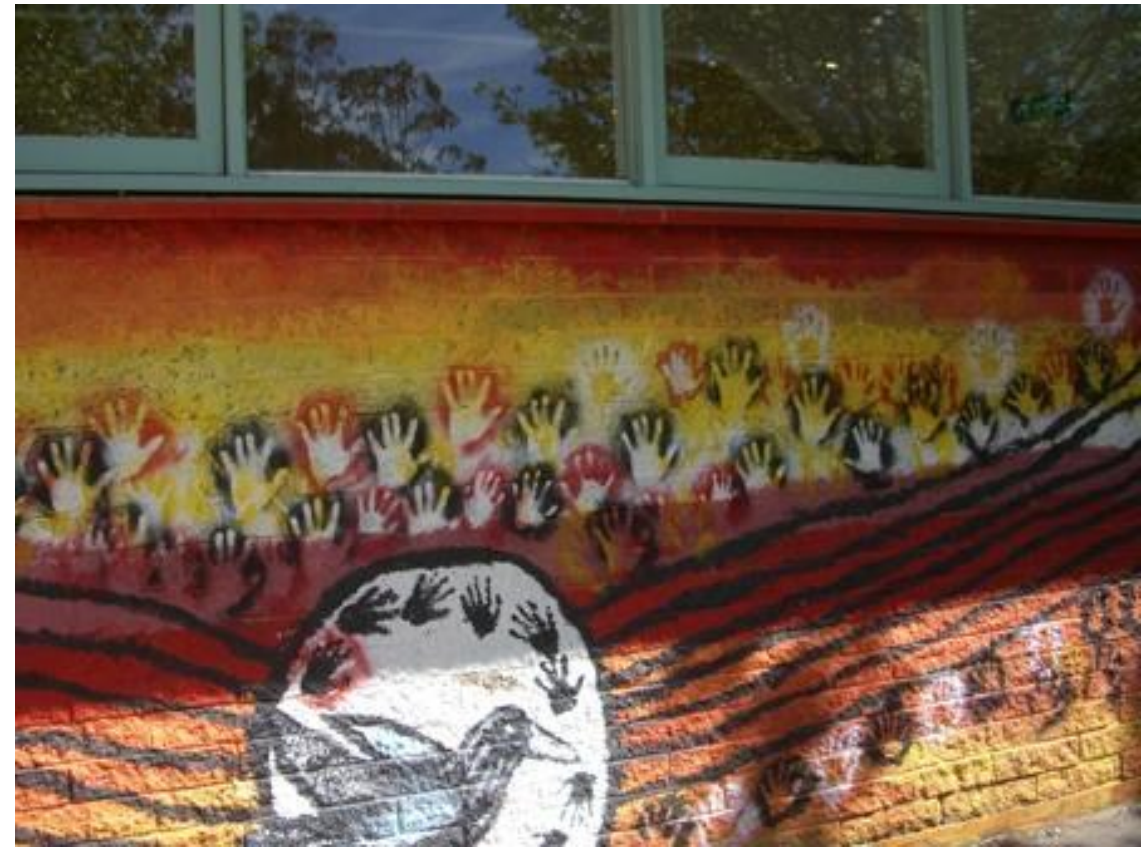

\subsection{A Definition}

"Proprio-performatives": ("proprio-" [proprius, one's own] "performative" [direct address]) where a hand image combines a sense of "ownership" with an act of communication-one which may be as straightforward as territorial marking. On my model both staple hand marks and those exhibiting digital variation are proprio-performative in character. As noted above, their primary meaning is that of direct address - to which further meaning can be attached. The simple example of a road stop sign (Figure 22) makes the point: it pictures a universally readable confrontational gesture of a human hand at the same time as it carries the symbolic message "STOP". Both meanings are accessible, though on very different terms. This is why it may be conjectured that one or both are in the Ngarinyin law elder Banggal's mind when he explains the "hand saying stop" stencil.

Figure 22. Road stop sign, USA.

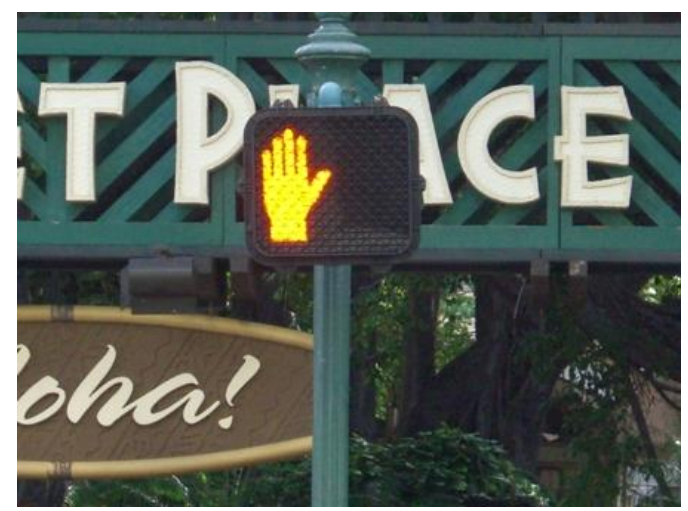


To summarize: even within sign-systems, signatures of individual identity remain, both as "author-identity" and as "act-identity". The hand image retains its quality of representing the proprietor, the author, through the author's original action. The stencil or print locks the maker into the image, effecting a personal statement that differentiates it from any other performative, such as a frontal Wandjina or the Milbrodale Baiame. The hand mark is a statement about origin and as such carries the authority of a recognizable, visually-read "voice". The reproduction of an individual hand is simultaneously a declaration about myself and from myself. It is proprio-performative.

\subsection{Exclusions}

As far as I can see, unless it can be argued that finger flutings warrant inclusion in the category, hand marks are uniquely "proprio-performative". In that they possess an autograph quality-amply demonstrated by the research of van Gelder and colleagues [146] - flutings can be said to be "proprio", but are they performative? On the face of it, they appear to lend themselves to patterning and the production of iconic images, both unrelated to human gesture as direct address. As the digitally-constructed animal heads in central Queensland, Australia, and even more complex ones recorded by Strecker at Acum Cave, Yucatan, show, hand manipulation registered in stencils can also produce striking non-hand images which capture attention in their own right. Strecker's intriguing examples of interrelated hands, at times holding an object, invite interpretation as figure-from-ground play: if we concentrate on the pigment area rather than finger and fist traces, independent shapes leap into view [147]. The question is at what point we cease to recognize the hand as hand. Certainly, profile depiction, as in Australia and Yucatan, moves a stencil away from its performative function. In some cases, figurative stencils will be received as neither proprio nor performative.

In general, embellished hands will sit on a scale of decreasing proprio-performative qualities in proportion to the nature and extent of decoration. I noted earlier, for example, that Borneo stencils with ornamentation resembling body-painting [54] might qualify on the grounds that the element of trace, i.e., their direct imaging of a specific bodily action, is not obscured. Decorated hands of the glove-like western Arnhem Land variety discussed above are, however, excluded on the grounds that they mask individual trace. They can be performative, but not proprio-performative. The same is true for images requiring the reproduction of the canonical form of hands through some labor-intensive activity like pecking. These too can be performatives, but will lack the featural identifiers of individuality which accompany trace. The small number of human feet which occur in the stencil repertoire suggests that, while they possess a "signature" quality, they do not have the impact of hands. Rizzolatti and Craighero ([138], p. 178) report that observation of (in this case object-related) foot/leg actions showed a partial overlapping of activations with those associated with mouth and hand action. As far as I know, there have not been specific experiments involving intransitive foot actions. In the case of animal feet stencils, these come into the category of intimate association discussed above. Their chief function would appear to lie within the composite symbolic language of hand signs and other images hypothesized by Walsh [80]. When it comes to pecked feet (Figure 23) of the kind which are found at "Panaramitee Tradition" sites in Australia or at Red Rock, Owens Valley, California, these are clearly human versions of animal track "implied narratives" [148] — a matter for discussion in a quite different context. 
Figure 23. Pecked human feet, Flinders Ranges, South Australia.

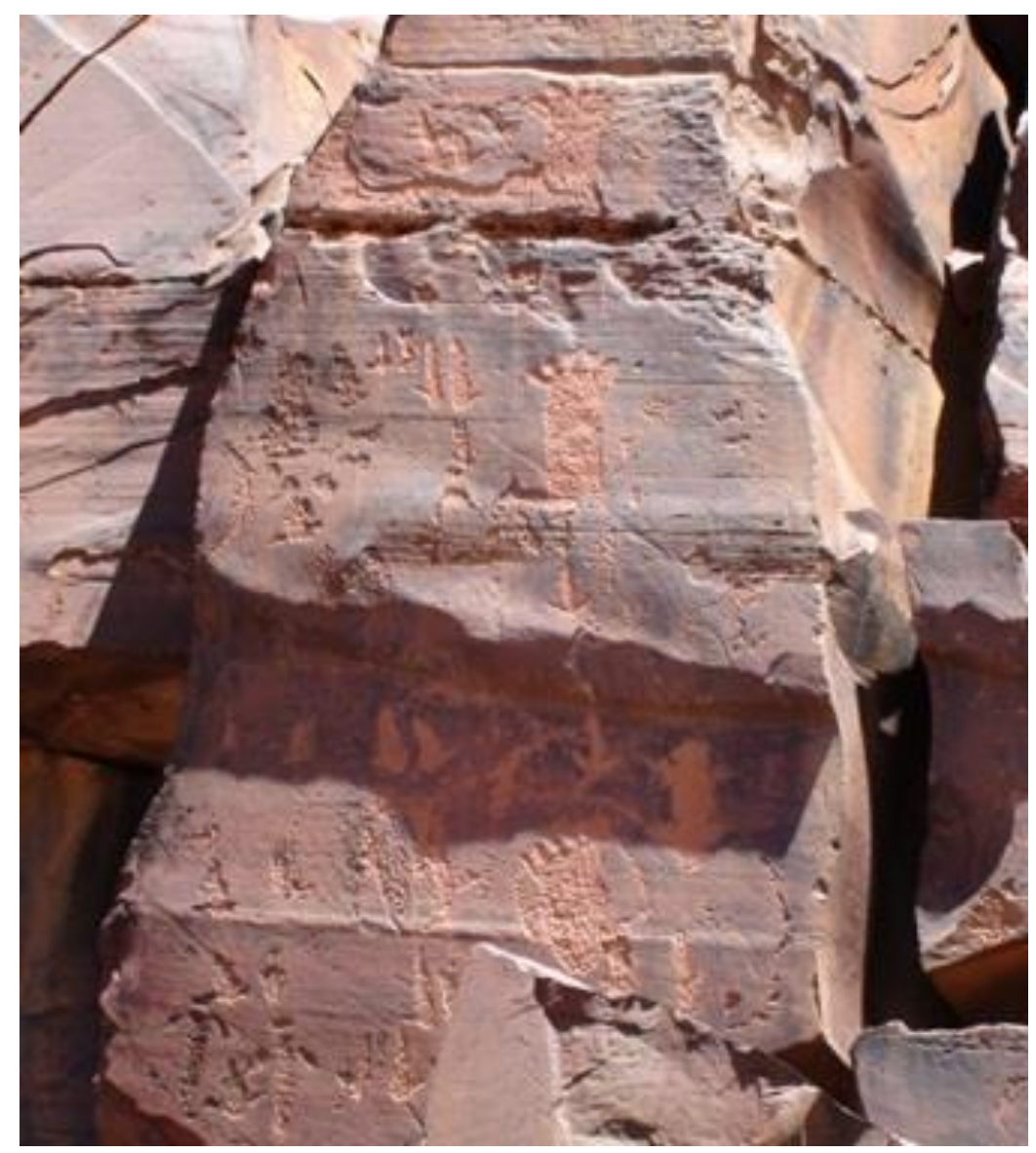

One attribute of stencils which should not interfere with their reception as proprio-performatives is their, in percentage terms, infrequent execution as sideways, upside-down or otherwise atypically rotated images (Figures 24 and 25). Merleau-Ponty cites medical conditions and experimental situations in which the subject experiences the world as inverted as suggesting that perceptual orientation is relative. (See Merleau-Ponty on the subject of "oriented being" [149], pp. 243-254.) However, Gibson stresses that, in normal situations, observers anchored by their awareness of gravity ([2], p. 71) will have a corresponding awareness of the up/down orientation of objects. In the context of hand marks, this fact might be expected to predispose us to accept familiar gravity-oriented postures. If so, that might help explain why atypically rotated images are uncommon. Still, atypical hand marks do not seem to present perceptual problems. While Gross et al. noted that in their experiment with macaque response to human and monkey hands "fingers pointing downward elicited very little response as compared to fingers pointing upward or laterally, the usual orientations in which the animal would see its own hand" ([16], p. 104), work on configuring processes by Reed and Stone indicates that, unlike faces and bodies, isolated body parts such as the arm are not more difficult to read when upside-down [150]. In the context of my argument, it seems safe to say that atypical hand marks come into the proprio-performative category. They continue to refer to the action that brought them into being (the "proprio") and retain their confrontational character (the "performative"). 
Figure 24. Charcamata, Santa Cruz, Argentina.

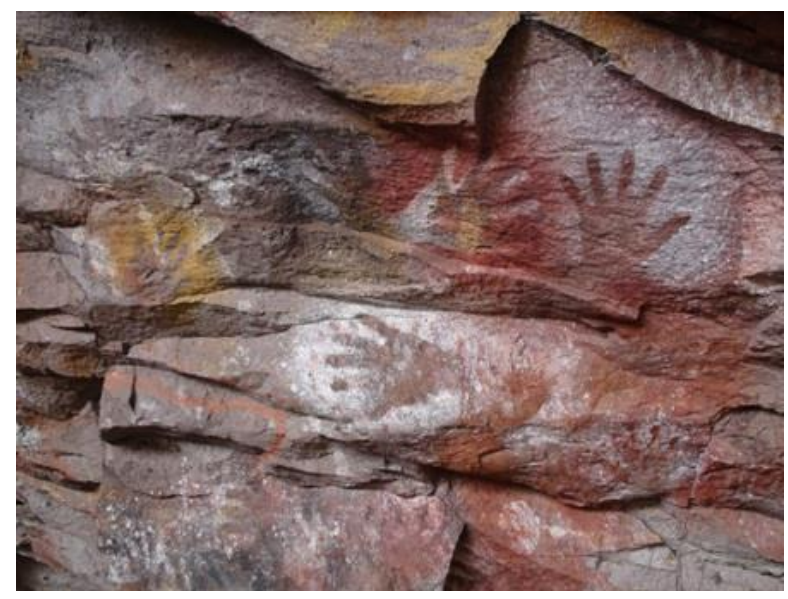

Figure 25. Carnarvon Gorge, Queensland, Australia. Courtesy B. Witemeyer.

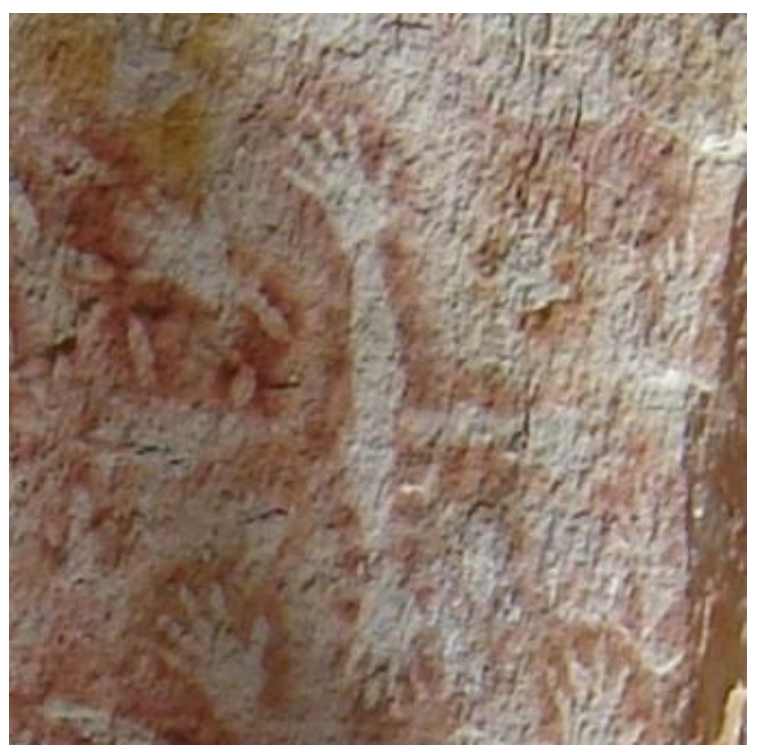

\subsection{A Doubly Performative Proprio Image}

As a footnote to the discussion of performatives and proprio-performatives I would like to remark on a pair of extraordinary rock art images from central Queensland that combine both Wandjina-style anthropomorphs and hand stencils in the same figure (Figure 26). The figures in question involve lattice-work, lines drawn freehand, and stencil additions in the form of hands. Verisimilitude has not been observed in the inclusion of hands, as the right-hand figure incorporates hands of similar orientation. Walsh observes that representation involving several techniques is not unique but certainly rare and that there is not much figurative art within the wider sandstone belt area. His idea, drawn from not too remote ethnography relating to mortuary rites, is that the lattice-work body of the anthropomorphic images may represent flayed human skins ([151], p.180). From this point of view it would be interesting to determine if the stencils and body of the figures belong to different episodes, and to ascertain whether the stencils were made by the same hand. The stencils in question do appear to have lattice-work superimposed on them, perhaps suggesting an equivalent of the Arnhem Land 
practice of transforming the hand marks of dead people. At any rate, here we see two performative art practices coming together in the one image: frontal figures and hand stencils.

Figure 26. Anthropomorphs with stenciled hands, central Queensland, Australia. Courtesy C. Sefton.

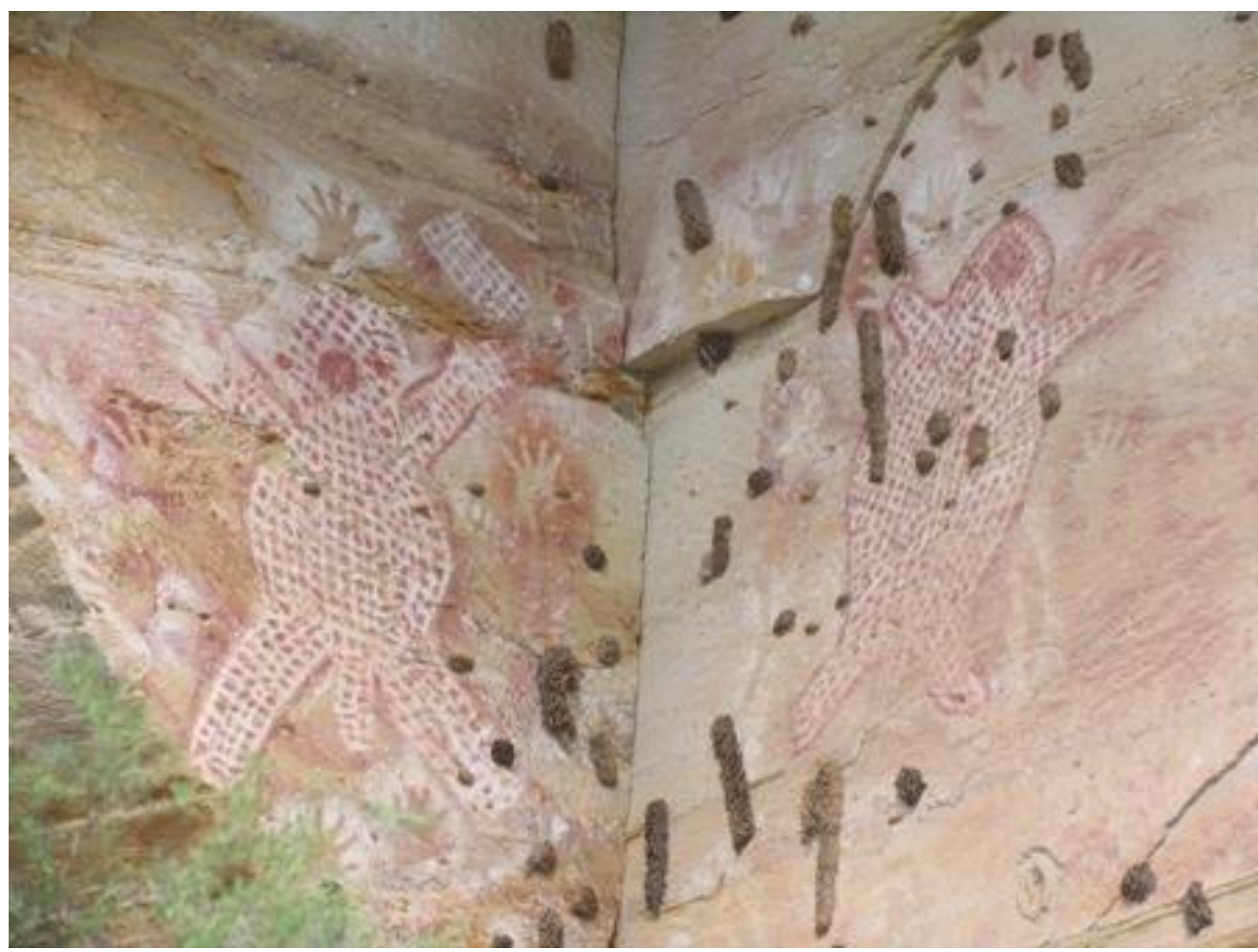

\section{Conclusion}

Insofar as they are accessible to observers beyond their original maker, through mirror-neuron activity, hand stencils and prints, while remaining as distinguishable from one another as finger-prints, bring into focus what human beings have in common with one another. We belong to the same species and have written into our motor systems the same possibilities for action. From our shared motor architecture and capacity for mirror neuron excitation when observing action flows the possibility of reciprocated understanding. In his 1991 Origins of the Modern Mind Merlin Donald sought to identify "vestigial structures" in cognition which might provide evidence for a pre-linguistic "missing link" in the evolutionary journey from episodic to symbolic culture, i.e., from apes to humans ([9], p. 165). In his account of cognitive evolution, he put forward mimesis, which he distinguished from imitation ("mimesis adds a representational dimension to imitation"), as the "missing link" in the shift to symbolic culture. His example was Australian Aboriginal dance, where "each dancer identifies with, and acts out the role of, a totemic animal". Mimesis might not always have existed as communication, he argued, but it "can be interpreted by others who possess a sufficient capacity for 
event perception" ([9], pp. 169-170, p. 172). In the context of a search for origins I wish to direct attention away from dance and towards hand stenciling and printing for what these might contribute to a scenario for the emergence of symboling (Figure 27).

Figure 27. Self-declarative ("proprio") hand-and-arm trace performative, Cueva de las Manos, Santa Cruz, Argentina.

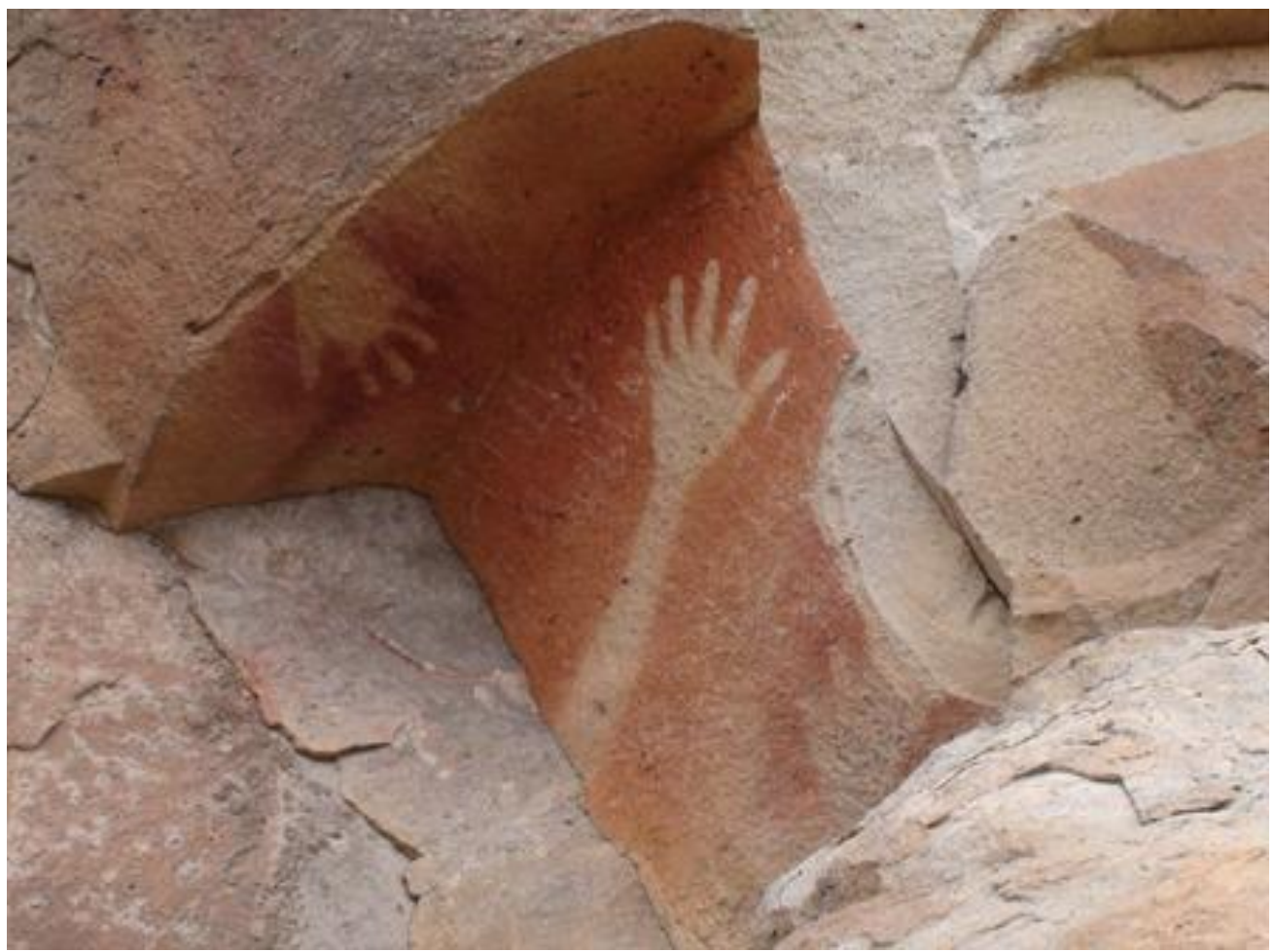

By way of conclusion to the argument for a category of propro-performatives consisting of stencils and prints, I want to introduce a new hypothesis, one which builds on what Rizzolatti and Arbib [20] and Rizzolatti and Craighero [138] suggest happened when the human mirror neuron system brought about the genesis of speech through the activation of that system by communicative gesture. Of course, the development of speech was conditional on the evolution of the vocal tract and its associated nervous system ([9], p. 117) but, apart from Arbib's assertion of habilis and erectus "language-readiness", the proponents of a role for mirror neurons do not venture an evolutionary chronology. Rizzolatti and Craighero simply state: "The mirror neuron communication system has a great asset: Its semantics is inherent to the gestures used to communicate" ([138], p. 184). Thinking about this symmetry as persuasive confirmation of the coactivation thesis, linking hand/arm and speech gesture in a neuronal mirroring, leads me to ask: why not a parallel in the genesis of visuographic language, in other words, a parallel linking hand/arm images to written language?

The notion of an external storage system centerd on "objects and their properties" [152] is a useful one here. The "exogram" as defined by Donald is "simply an external memory record of an idea". My suggestion, based on the unique status I have proposed for hand marks, relates to what Donald labels "systems of exogram storage" ([9], pp. 314-319). (See also Bednarik in this issue of Arts.) Without such systems as written language most of what makes up our lives in the modern world would be impossible. The question is: where did "retrieval" systems have their beginnings? One answer might 
be that they have originated in transposed gestural language, viz. the so-called mutilated hands, which have provoked so much speculation in rock art studies. What is important for this hypothesis is that transposed sign systems are in turn reliant on the proprio-performative operation of hand traces, traces which are iconic in character. Bednarik has canvassed the idea of a role for finger flutings in the evolution of exograms. While there are other candidates ([152], pp. 11-14), hand traces have the advantage of satisfying the condition of iconicity Arbib selects as, in all likelihood, playing an important role in the evolution of language: "Once an organism has an iconic gesture, it can both modulate that gesture and/or symbolize it (non-iconically) by 'simply' associating a vocalization with it" ([18], p.117). What is needed for symbolic elaboration is a conveniently identifiable stock icon (easily provided by hand gesture and its rock-art trace equivalent), the variability of which allows for, indeed promotes, the evolution of an extended "repertoire" of signs.

On this proposed model, which runs parallel to Arbib's for the evolution of language, the hand mark, itself an exogram, emerges as the first external term in an exchange of meaning, i.e., a symbolic exchange, on the basis of which an entire exogram system might be built. Hand traces themselves may have arisen in accidental contexts involving ochre or other staining substances, or they may have their origin in imitations of human and animal tracks or, alternatively, observed shadows of hands. They may have arisen simply through an everyday locomotor act of exploring the world: the human equivalent of an animal spoor. By accident or design, the marks are made and taken up for communicative purposes: this much is indisputable. While the notion of hand-marking as central to the genesis of graphic communication may be a bridge too far for some, this at least can be asserted: whatever other candidates there may be (dancing, body-painting, weaving, threading beads), hand marks must be seen as having a significant role in, and might just be an originator of, expanded human cognition through quasi-representation and proto-writing: the First Cause we all wish to stumble over in our scanning of the past.

\section{Acknowledgments}

A version of this paper was presented in Session 7 (on hands in world rock art) of IFRAO, Albuquerque, in May this year. Gratitude is extended to the moderators, Jane Kolber, Hipólito Collado Giraldo and José Julio García Arranz and session participants, in particular Dr Graeme Ward, Research Fellow, Australian Institute of Aboriginal and Torres Strait Studies, for alerting me to relevant Ngarinyin ethnography relating to performative hand stencils. I thank the Kimbell Art Museum, Fort Worth, Texas, for permission to reproduce the painting by George Stubbs, and Caryll Sefton, Barbara Witemeyer and "ben" Gunn for permitting publication of their photographs; also Mercedes Podestá and the late Grahame Walsh for supplying documentation relating to Cueva de las Manos and Carnarvon Gorge. I am indebted to Max Davidson for showing me Charlie Mangulda's country at Mt Borradaile and to the late Bill Neidjie for showing me his country at Kakadu.

\section{Conflicts of Interest}

The author declares no conflict of interest. 


\section{References}

1. Napier, J. Hands, revised by R.H. Tuttle; Princeton University Press: Princeton, NJ, USA, 1993.

2. Gibson, J.J. The Senses Considered as Perceptual Systems; Houghton Mifflin: Boston, MA, USA, 1966.

3. McPherron, S.P.; Alemseged, Z.; Marean, C.; Wynn, J.G.; Reed, D.; Geraads, D.; Bobe, R.; Béarat, H. Evidence for stone-tool-assisted consumption of animal tissues before 3.39 million years ago at Dikka, Ethiopia. Nature 2010, 466, 857-860.

4. McPherron, S.P.; Alemseged, Z.; Marean, C.; Wynn, J.G.; Reed, D.; Geraads, D.; Bobe, R.; Béarat, H. Tool-marked bones from before the Oldowan change the paradigm. Proc. Natl. Acad. Sci. USA 2011, 108, E116.

5. Marzke, M.W.; Shackley, M.S. Hominid hand use in the pliocene: Evidence from experimental archaeology and comparative morphology. J. Hum. Evol. 1986, 15, 439-460.

6. Semaw, S.; Renne, P.; Harris, J.W.K.; Feibel, C.S.; Bernor, R.L.; Fesseha, N.; Mowbray, K. 2.5 million-year-old stone tools from Gona, Ethiopia. Nature 1997, 385, 333-336.

7. Leakey, L.S.B.; Tobias, P.V.; Napier, J.R. A new species of the genus Homo from Olduvai Gorge. Nature 1964, 202, 7-9.

8. Marzke, M.W.; Marzke, R.F. Evolution of the human hand: Approaches to acquiring, analysing and interpreting the anatomical evidence. J. Anat. 2000, 197, 121-140.

9. Donald, M. Origins of the Modern Mind: Three Stages in the Evolution of Culture and Cognition; Harvard University Press: Cambridge, MA, USA, 1993.

10. Jones, L.A.; Lederman, S.J. Human hand Function; Oxford University Press: Oxford, UK, 2006.

11. Tocheri, M.W.; Marzke, M.W.; Liu, D.; Bae, M.; Jones, G.P.; Williams, R.C.; Razdan, A. Functional capabilities of modern and fossil hominid hands: Three-dimensional analysis of trapezia. Am. J. Phys. Anthropol. 2003, 122, 103-112.

12. Darwin, C. The Descent of Man. In The Origin of Species by means of natural selection; The Descent of Man and selection in relation to sex; William Benton and the University of Chicago: Chicago, IL, USA, 1952, pp. 253-659.

13. Rolian, C.; Lieberman, D.E.; Hallgrimsson, B. The coevolution of human hands and feet. Evolution 2010, 64, 1558-1568.

14. Kivell, T.L.; Kibil, J.M.; Churchill, S.E.; Schmid, P.; Berger, L.R. Australopithecus sediba hand demonstrates mosaic evolution of locomotor and manipulative abilities. Science 2011, 333, 1411-1417.

15. Peeters, R.; Simone, L.; Nelissen, K.; Fabbri-Destro, M.; Vanduffel, W.; Rizzolatti, G.; Orban, G.A. The representation of tool use in humans and monkeys: Common and uniquely human features. J. Neurosci. 2009, 29, 11523-11539.

16. Gross, C.G.; Rocha-Miranda, C.E.; Bender, D.B. Visual properties of neurons in inferotemporal cortex of the macaque. J. Neurophysiol. 1972, 35, 96-111.

17. Penfield, W.; Rasmussen, T. The Cerebral Cortex of Man, A Clinical Study of Localization and Function; The Macmillan Company: New York, NY, USA, 1952.

18. Arbib, M.A. From monkey-like action recognition to human language: An evolutionary framework for neurolinguistics. Behav. Brain Sci. 2005, 28, 105-124. 
19. Rizzolatti, G.; Fogassi, L.; Gallese, V. Neurophysiological mechanisms underlying the understanding and imitation of action. Nat. Rev. Neurosci. 2001, 2, 661-670.

20. Rizzolatti, G.; Arbib, A. Language within our grasp. Trends Neurosci. 1998, 21, 188-194.

21. Lorblanchet, M. La Naissance de l'Art: Genèse de l'art préhistorique dans le monde; Ėditions Errance: Paris, France, 1999.

22. Clottes, J.; Courtin, J. The Cave Beneath the Sea, Paleolithic Images at Cosquer; M. Garner, translator; Harry N. Abrams: New York, NY, USA, 1996.

23. Pike, A.W.G.; Hoffmann, D.L.; Garcia-Diez, M.; Pettit, P.B.; Alcolea, J.; de Balbin, R.; González-Sainz, C.; de las Heras, C.; Lasheras, J.A.; Montes, R.; et al. U-Series dating of paleolithic art in 11 Caves in Spain. Science 2012, 336, 1409-1413.

24. Bednarik, R.G. U-Th analysis and rock art: A response to Pike et al. Rock Art Res. 2012, 29, 244-246.

25. Layton, R. Australian Rock Art: A New Synthesis; Cambridge University Press: Cambridge, UK, 1992.

26. Mulvaney, K. What to do on a rainy day. Rock Art Res. 1996, 13, 3-20.

27. Roberts, D.A.; Parker, A. Ancient Ochres: The Aboriginal Rock Paintings of Mt Borradaile; J.B. Books Australia: Marleston, Australia, 2003.

28. Dubey-Pathek, M.; Clottes, J. Handprints in the Rock Art and Tribal Art of Central India. In International Federation of Rock Art Organizations 2013 Proceedings, American Indian Rock Art; ARARA, Glendale, AZ, USA, 2013; Volume 40, pp. 373-382.

29. Efremov, J.A. Taphonomy: New branch of paleontology. Pan-Am. Geol. 1940, 74, 81-93.

30. Bednarik, R.G. A unified theory for palaeoart studies. Rock Art Res. 2006, 23, 85-88.

31. Clottes, J., Ed. Return to Chauvet Cave: Excavating the Birthplace of Art: The First Full Report; Thames and Hudson: London, UK, 2003.

32. Gunn, R.G.; Douglas, L.C.; Whear, R.L. An example of stencil masking from the Arnhem Land Plateau. Rock Art Res. 2012, 29, 238-241.

33. Barrière, C.; Sueres, M. Les mains de Gargas. Les Dossiers d'Archéologie 1993, 178, 46-55.

34. Breuil, H. Four Hundred Centuries of Cave Art; Boyle, M.E., translator; Hacker Art Books: New York, NY, USA, 1979, Boyle, M.E.

35. Bednarik, R.G.; Achrati, A.; Consens, M.; Coimbra, F.; Dimitriadis, G.; Huisheng, T.; Muzzolini, A.; Seglie, D.; Sher, Y.A. Rock Art Glossary: A Multilingual Dictionary; Occasional AURA Publication 16; AURA: Melbourne, Australia, 2010.

36. Bahn, P.G.; Vertut, J. Journey through the Ice Age; Weidenfeld and Nicolson: London, UK, 1997.

37. Keyser, J.D.; Klassen, M.A. Plains Indian Rock Art; University of Washington Press: Seattle, WA, USA, 2001.

38. Gradin, C.J.; Aschero, C.A.; Aguerre, A.M. Investigaciones Archeológicas en la Cueva de las Manos, Estancia Alto Rio pinturas (Provincia de Santa Cruz). Relaciones da la Sociedad de Antropologia 1976, 10, 201-250.

39. Podestá, M.M.; Paunero, R.S.; Rolandi, D.S. El Arte Rupestre de Argentina Indigena, $1^{a}$ parte: Patagonia; Unión Académique Internationale, Argentina, 2005.

40. McCarthy, F.D. Rock Art of the Cobar Pediplain in Central Western New South Wales; Australian Institute of Aboriginal Studies: Canberra, Australia, 1976. 
41. Basedow, H. The Australian Aboriginal; F. W. Preece \& Sons: Adelaide, Australia, 1925.

42. Tresize, P. Dream Road, a Journey of Discovery; Allen \& Unwin: St Leonards, Australia, 1997.

43. Gunn, R.G. Hand sizes in rock art: Interpreting the measurements of hand stencils and prints. Rock Art Res. 2006, 2, 97-112.

44. Greer, M.; Greer, J. Handprints in Montana rock art. Plains Anthropol.: J. Plains Anthropol. Soc. 1999, 44, 59-71.

45. Leroi-Gourhan, A. The Dawn of European Art: An Introduction to Palaeolithic Cave Painting; Champion, S., translator; Cambridge University Press: Cambridge, UK, 1982.

46. Freers, S. The hand prints at CA-RIV-114: A forensic and anthropometric study. Am. Rock Art Res. 2001, 27, 319-332.

47. Bednarik, R. Children as Pleistocene artists. Rock Art Res. 2008, 25, 173-182.

48. Chazine, J.-M.; Noury, A. Sexual determination of hand stencils on the main panel of the Gua Masri II cave (East -Kalimantan/Borneo - Indonesia). Int. Newsl. Rock Art 2006, 44, 21-26.

49. Manning, J.T.; Scutt, D.; Wilson, J.; Lewis-Jones, D.I. The ratio of 2nd to 4th digit length: A predictor of sperm numbers and concentrations of testosterone, luteinising hormone and oestrogen. Hum. Reprod. 1998, 13, 3000-3004.

50. Snow, D.R. Sexual dimorphism in Upper Palaeolithic hand stencils. Antiquity 2006, 80, 390-404.

51. Nelson, E.C.; Manning, J.T.; Sinclair, G.M. Using the length of the 2nd to 4th digit ratio (2D/4D) to sex cave art hand stencils: Factors to consider. Beyond Farming 2006, 1, 1-7.

52. Brůžek, J.; Lázničková, M.; Galeta, P.; Maestracci, J. Les empreintes de mains dans l'art parietal: Possibilités et limites d'interprétations mises en relief par l'anthropologie medico-légale. In $L$ 'art pléistocène dans le monde; Actes de congrés IFRAO, Tarasocon-sur-Ariège, septembre 2010. $\mathrm{N}^{\circ}$ spécial de Préhistoire, Art et Sociétés; Clottes, J., Ed.; Bulletin de la Société Préhistorique Ariège-Pyrénées, LXV-LXVI, Ariège, France, 2010-2011; pp. 1197-1206.

53. Freers, S. Stature and Gender Projections from Pictograph Handprint Evidence in Southern California. Unpublished paper presented in Session 7, In Proceedings of Ancient Hands around the World, International Federation of Rock Art Organizations Congress, Albuquerque, NM, USA, 26-31 May 2013.

54. Chazine, J.-M. Some clues from Borneo for deciphering hand stencils. In International Federation of Rock Art Organizations 2013 Proceedings, American Indian Rock Art; ARARA: Glendale, AZ, USA; Volume 40, pp. 363-372.

55. Robins, A.; Nowell, A. Who Drew All Over the Wall? The Applicability of 2D/4D Ratio for Sexing Children's Hand Stencils in Rock Art. Unpublished paper presented in Session 7, In Proceedings of Ancient Hands Around the World, International Federation of Rock Art Organizations Congress, Albuquerque, NM, USA, 26-31 May 2013.

56. Beaumont, P.B.; Bednarik, R.G. A Brief Overview of Major Pleistocene Rock Art Sites in Sub-Sharan Africa. In L'art pléistocène dans le monde; Actes de congrés IFRAO, Tarasocon-surAriège, septembre 2010: $N^{\circ}$ spécial de Préhistoire, Art et Sociétés; Clottes, J., Ed.; Bulletin de la Société Préhistorique Ariège-Pyrénées, Ariège, France, LXV-LXVI, 2010-2011; pp. 541-548.

57. Beaumont, P.B.; Bednarik, R.G. Tracing the emergence of palaeoart in sub-Saharan Africa. Rock Art Res. 2013, 30, 33-54.

58. Bednarik, R.G. The earliest evidence of palaeoart. Rock Art Res. 2003, 20, 89-135. 
59. Bednarik, R.G. A figurine from the African Acheulian. Curr. Anthropol. 2003, 44, 405-413.

60. Henshilwood, C.S.; d'Errico, F.; van Niekerk, K.L.; Coquinot, Y.; Jacobs, Z.; Lauritzen, S.-E.; Menu, M.; García-Moreno, R. A 100,000-year-old ochre-processing workshop at Blombos Cave, South Africa. Science 2011, 334, 219-222.

61. Chaloupka, G. Journey in Time, the World's Longest Continuing Art Tradition; William Heinemann Australia: Chatswood, Australia, 1993.

62. Petru, S. Red, black or white? The dawn of color symbolism. Doc. Praehist. 2006, 33, 203-208.

63. Wainright, I.N.M.; Helwig, K.; Rolandi, D.S.; Gradin, C.; Podestá, M.M.; Onetto, M.; Achero, C.A. Rock Paintings Conservation and Pigment Analysis at Cueva de las Manos and Cerro de los Indios, Santa Cruz (Patagonia). In ICOM Committee for Conservation, 13th Triennial Meeting, Rio de Janeiro, 22-27 September 2002; Vontobel, R., Ed.; James and James (Science Publishers): London, UK, 2002; pp. 582-589.

64. Gradin, C.J.; Aguerre, A.M.; Mattar, M.C. Cueva de las Manos (Pamphlet); Hotel Belgrano: Perito Morena, Santa Cruz, Argentina, 2007.

65. Leroi-Gourhan, A. Les Mains de Gargas. Essai pour une étude d'ensemble. Bulletin de la Société préhistorique française. Études et travaux 1967, 64, 107-122.

66. Taçon, P.S.C. From Rainbow Snakes to 'X-Ray' Fish: The Nature of the Recent Rock Painting Tradition of Western Arnhem Land, Australia. Ph.D. Unpublished Thesis, Australian National University, Canberra, Australia, 1989.

67. Elkin, A.P. Cave paintings in southern Arnhem Land. Oceania 1952, 22, 245-255.

68. Gunn, R.G. Patterned hand prints: A unique form from Central Australia. Rock Art Res. 1998, 15, 75-80.

69. Grant, C. Canyon de Chelly: Its People and Rock Art; The University of Arizona Press: Tucson, AZ, USA, 1978.

70. Manhire, A. The role of hand prints in the rock art of the south-western Cape. S. Afr. Archaeol. Bull. 1998, 53, 98-108.

71. Van Ryssen, W.J.J. The origin of certain images in the rock art of southern Africa, and Comments. Rock Art Res. 1985, 2, 146-157.

72. Malotki, E.; Weaver, D.E., Jr. Stone Chisel and Yucca Brush; Kiva Publishing: Walnut, CA, USA, 2002.

73. Bahn, P.G. The Cambridge Illustrated History of Prehistoric Art; Cambridge University Press: Cambridge, UK, 1998.

74. Breschini, G.S.; Haversat, T. The Esselen Indians of the Big Sur Country: The Land and the People; Coyote Press: Salinas, CA, USA, 2004.

75. Tench, W. A Narrative of the Expedition to Botany Bay. In Sydney's First Four Years; Fitzhardinge, L.F., Ed.; Library of Australian History: Sydney, Australia; 1979.

76. Collins, D. An Account of the English Colony in New South Wales, Volume I; Fletcher, B.H., Ed.; A.H. \& A.W. Reed: Sydney, Australia, 1975.

77. Roth, W.E. Ethnological Studies among the North-West-Central Queensland Aborigines; Government Printer: Brisbane, Australia, 1897.

78. Howitt, A.W. The Native Tribes of South-East Australia, Facsimile ed.; Aboriginal Studies Press: Canberra, Australia, 1996. 
79. Leroi-Gourhan, A. The hands of Gargas: Toward a general study. October 1986, 37, 18-34; Michelson, A., translator. Available online: http://www.jstor.org/stable/778515 (accessed on 24 November 2012).

80. Walsh, G.L. Mutilated hands or signal stencils? A consideration of irregular hand stencils from central Queensland. Aust. Archaeol. 1979, 9, 33-41.

81. Tresize, P. Rock Art of South-East Cape York; Australian Institute of Aboriginal Studies No. 24, Prehistory and Material Culture Series No 4; Australian Institute of Aboriginal Studies: Canberra, Australia, 1971.

82. Wright, B. The significance of hand motif variations in the stenciled art of the Australian Aborigines, and Comments. Rock Art Res. 1985, 2, 3-10.

83. Groenen, M. Les représentations de mains negatives dans les grottes de Gargas et de Tibaran (Hautes-Pyrénées): Approche méthodologique. Bulletin Societé royale belge d'Anthropologie et de Préhistoire 1988, 99, 81-113.

84. Hooper, A. Further information on the prehistoric representations of human hands in the Cave of Gargas. Med. Hist. 1980, 24, 214-216.

85. Morwood, M.J. Visions from the Past: The Archaeology of Aboriginal Art; Allen \& Unwin: Crows Nest, Australia, 2002.

86. Davis, W. Commentary on Wright [82]. Rock art Res. 1985, 2, 17.

87. Le Quellec, J.-L. Can One "Read" Rock Art? An Egyptian Example. In Iconography without Texts; Taylor, P., Ed.; Warburg Institute: London, UK, 2008; pp. 25-42.

88. Bates, D. The Native Tribes of Western Australia; White, I., Ed.; National Library of Australia: Canberra, Australia, 1985.

89. Ucko, P.J.; Rosenfeld, A. Palaeolithic Cave Art; Weidenfeld \& Nicolson: London, UK, 1967.

90. Basedow, H. Knights of the Boomerang; The Endeavour Press: Sydney, Australia, 1935.

91. Flood, J. Rock art of the Koolburra Plateau, north Queensland, with Comment. Rock Art Res. 1987, 4, 91-126.

92. Dobrez, L.; Dobrez, P. Rock art animals in profile: Visual recognition and the principles of Canonical Form. Rock Art Res. 2013, 30, 75-90.

93. Tsakiris, M.; Schütz-Bosbach, S.; Gallagher, S. On agency and body-ownership: Phenomenological and neuroscience reflections. Conscious. Cogn. 2007, 16, 645-660.

94. Onetto, M.; Podestá, M.M. Cueva de las Manos: An Outstanding Example of a Rock Art Site in South America. In Adoranten 2011; Scandinavian Society for Prehistoric Art, Tanums Hällristningsmuseum Underslös: Tanumshed, Sweden, 2011; pp. 67-78.

95. Mathews, R.H. The rock paintings of the Australian Aborigines. R. Geogr. Soc. Australas. Qld. Branch Proc. Trans. 1896, 11, 86-105.

96. Mathews, R.H. Rock paintings by the Aborigines in caves on Bulgar Creek, near Singleton. $J$. $R$. Soc. N. S. W. 1893, 27, 353-358.

97. Moore, D.R. The Hand Stencil as Symbol. In Form in Indigenous Art: Schematisation in the Art of Aboriginal Australia and Prehistoric Europe; Prehistory and Material Culture Series No. 13; Ucko, P.J., Ed.; Australian Institute of Aboriginal Studies: Canberra, Australia, 1977; pp. 318-324.

98. Elkin, P. Aboriginal Men of High Degree; University of Queensland Press: St Lucia, Australia, 1977. 
99. Eliade, M. Myths, Dreams and Mysteries; Michelson, A., translator. Fontana Library: London, UK, 1968.

100. Baker, N. Milbrodale Core Hole: Heritage due Diligence Study, Aboriginal and Historic Heritage; Report A12002RP1, prepared for AGL Energy Ltd.: Sydney, Australia, 13 July 2012.

101. Tresize, P. Commentary on Wright [82]. Rock Art Res. 1985, 2, 16.

102. Bouissac, P. Probing prehistoric cultures: Data, dates and narratives. Rock Art Res. 2006, 23, 89-96.

103. Forge, A. Handstencils: Rock Art or not Art. In Rock Art and Prehistory: Papers Presented to Symposium G of the AURA Congress, Darwin 1988; Bahn, P., Rosenfeld, A., Eds.; Oxbow Books: Oxford, UK, 1991; pp. 39-44.

104. Peterson, N. Totemism yesterday: Sentiment and local organization among the Australian Aborigines. Man (new series) 1972, 7, 12-32.

105. Flood, J. Rock Art of the Dreamtime; Angus \& Robertson: Sydney, Australia, 1997.

106. Layton, R. The Alawa Totemic Landscape: Ecology, Religion and Politics. In The Archaeology and Anthropology of Landscape, One World Archaeology 30; Ucko, P.J., Layton, R., Eds.; Routledge: London, UK, 1999; pp. 221-241.

107. Gibson, E.J. Ontogenesis of the Perceived Self. In The Perceived Self: Ecological and Interpersonal Sources of Self-Knowledge; Neisser, U., Ed.; Cambridge University Press: Cambridge, UK, 1993; pp. 25-42.

108. Gibson, J.J. The Ecological Approach to Visual Perception; Houghlin Mifflin: Boston, MA, USA, 1979.

109. Neisser, U. The Self Perceived. In The Perceived Self: Ecological and Interpersonal Sources of Self-Knowledge; Neisser, U., Ed.; Cambridge University Press: Cambridge, UK, 1993; pp. 3-21.

110. Gallagher, S. Philosophical conceptions of the self: Implications for cognitive science. Trends Cogn. Sci. 2000, 4, 14-21.

111. Gallagher, S. How the Body Shapes the Mind; Clarendon Press: Oxford, UK, 2005; pp. 173-178.

112. Tsakiris, M.; Haggard, P.; Franck, N.; Mainy, N.; Sirigu, A. A specific role for efferent information in self-recognition. Cognition 2005, 96, 215-231.

113. Dobrez, L.; Dobrez, P. Canonical form and the identification of rock art figures. Am. Indian Rock Art 2013, 39, 114-129.

114. Knoblich, G.; Thornton, I.; Grosjean, M.; Shiffrar, M. Integrating Perspectives on Human Body Perception. In Human Body Perception from the Inside Out; Knoblich, G., Thornton, I., Grosjean, M., Shiffrar, M., Eds.; Oxford University Press: Oxford, UK, 2006; pp. 3-8.

115. Shontz, F.C. The Ecological Self in Historical Context. In The Perceived Self: Ecological and Interpersonal Sources of Self-Knowledge, Neisser, U., Ed.; Cambridge University Press: Cambridge, UK, 1993; pp. 89-101.

116. Bermúdez, J.L. Ecological Perception and the Notion of a Nonconceptual Point of View. In The Body and the Self; Bermúdez, J.L., Marcel, A., Eilan, N., Eds.; The MIT Press: Cambridge, MA, USA, 1998; pp. 153-173.

117. Lee, D.N. Body-Environment Coupling. In The Perceived Self: Ecological and Interpersonal Sources of Self-Knowledge; Neisser, U., Ed.; Cambridge University Press: Cambridge, UK, 1993; pp. 43-67. 
118. Kalckert, A.; Ehrsson, H.H. Moving a rubber hand that feels like your own: A dissociation of ownership and agency. Front. Hum. Neurosci. 2012, 6, 1-14.

119. Walsh, L.D.; Moseley, G.L.; Taylor, J.L.; Gandevia, S.C. Proprioceptive signals contribute to the sense of body ownership. J. Physiol. 2011, 589, 3009-3021.

120. Maravita, A. From "Body in the Brain" to "Body in Space". In Human Body Perception from the Inside Out; Knoblich, G., Thornton, I., Grosjean, M., Shiffrar, M., Eds.; Oxford University Press: Oxford, UK, 2006; pp. 65-88.

121. Holmes, N.P.; Spence, C. Beyond the Body Schema: Visual, Prosthetic, and Technological Contributions to Bodily Perception and Awareness. In Human Body Perception from the Inside Out; Knoblich G., Thornton, I., Grosjean, M., Shiffrar, M., Eds.; Oxford University Press: Oxford, UK, 2006; pp. 15-64.

122. Rosenfeld, A. Rock art and rock markings. Aust. Archaeol. 1999, 49, 28-33.

123. Clegg, J. About pictures of echidnas and cats. Rock Art Res. 1995, 12, 11-13.

124. Mitchell, R.W. Multiplicities of Self. In Self-Awareness in Animals and Humans: Developmental Perspectives; Parker, S.T., Mitchell, R.W., Bocca, M.L., Eds.; Cambridge University Press: Cambridge, UK, 1994; pp. 81-107.

125. Gallup, G.G., Jr. Self-Recognition: Research Strategies and Experimental Design. In Self-Awareness in Animals and Humans: Developmental Perspectives; Parker, S.T., Mitchell, R.W., Bocca, M.L., Eds.; Cambridge University Press: Cambridge, UK, 1994; pp. 35-50.

126. Rochat, P.; Zahavi, D. The uncanny mirror: A re-framing of mirror self-experience. Conscious. Cogn. 2011, 20, 204-213.

127. Merleau-Ponty, M. The Child's Relations with Others. In The Primacy of Perception; Cobb, W., translator; Merleau-Ponty, M., Ed.; Northwestern University Press: Evanston, IL, USA, 1964; pp. 96-155.

128. Anderson, J.R. The Monkey in the Mirror: A Strange Conspecific. In Self-Awareness in Animals and Humans: Developmental Perspectives; Parker, S.T., Mitchell, R.W., Bocca, M.L., Eds.; Cambridge University Press: Cambridge, UK, 1994; pp. 315-329.

129. Freyd, J.J.; Finke, R.R. Representational Momentum. J. Exp. Psychol. 1984, 10, 126-132.

130. Dobrez, L. American Ikon: How to choose an ARARA logo. Am. Indian Rock Art 2012, 38, $145-164$.

131. Dobrez, L. A Rock Art Typology: Narrative and Non-Narrative Figurative Representation. In Aesthetics and Rock Art III Symposium; BAR International Series 1818; Heyd, T., Clegg, J., Eds.; Archaeopress: Oxford, UK, 2008; pp. 29-33.

132. Dobrez, L. What representations tell us about what we see, with Commentary. Purakala, Journal of Rock Art Society of India 2010-2012, 20-21, 23-41.

133. Ngarjno, Ungudman, Banggal, \& Nyawarra. Gwion Gwion: Dulwan Mamaa. Secret and Sacred Pathways of the Ngarinyin Aboriginal People of Australia; Doring J., Ed.; Könemann: Köln, Germany, 2000.

134. Urgesi, C.; Moro, V.; Candidi, M.; Aglioti, S.M. Mapping implied body actions in the human motor system. J. Neurosci. 2006, 26, 7942-7949.

135. Watson, B. The neuropsychology of animism and implied motion. Rock Art Res. 2010, 27, 79-80. 
136. Freyd, J. J. The mental representation of movement when static stimuli are viewed. Percept. Psychophys. 1983, 33, 575-581.

137. Kelly, M.H.; Freyd, J. Explorations of representational momentum. Cogn. Psychol. 1987, 19, 369-401.

138. Rizzolatti, G.; Craighero, L. The mirror-neuron system. Annu. Rev. Neurosci. 2004, 27, 169-192.

139. Senior, C.; Barnes, J.; Giampietro, V.; Simmons, A.; Bullmore, E.T.; Brammer, M.; David, A.S. The functional neuroanatomy of implicit-motion perception or representational momentum. Curr. Biol. 2000, 10, 16-22.

140. Kourtzi, Z.; Kanwisher, N. Activation in human MT/MST by static images with implied motion. J. Cogn. Neurosci. 2000, 12, 48-55.

141. Proverbio, A.M.; Riva, F.; Zani, A. Observation of static pictures of dynamic actions enhances the activity of movement-related brain areas. PLoS One 2009, 4, e5389. Available online: http://www.plosone.org/article/info:doi:10.1371/journal.pone.0005389 (accessed on 21 July 2013).

142. Johnson-Frey, S.H.; Maloof, F.R.; Newman-Norlund, R.; Farrer, C.; Inati, S.; Grafton, S.T. Actions or hand-object interactions? Human inferior frontal cortex and action observation. Neuron 2003, 39, 1053-1058.

143. Calipers (pseud.). A Grim Experience on the Nardoo Creek. The Argus (Melbourne, Australia), 16 May 1891, p. 13.

144. Freedberg, D.; Gallese, V. Motion, emotion and empathy in esthetic experience. Trends Cogn. Sci. 2007, 11, 197-203.

145. Achrati, A. Rock art, perspectival representations and mirror neurons. Rock Art Res. 2013, 30, $3-21$.

146. Van Gelder, L. Ten Years in Rouffignac Cave: A Collective Report on Findings from a Decade of Finger Flutings Research. In L'art pléistocène dans le monde; Actes de congrés IFRAO, Tarasocn-sur-Ariège, septembre 2010. $\mathrm{N}^{\circ}$ spécial de Préhistoire, Art et Sociétés; Clottes, J., Ed.; Bulletin de la Société Préhistorique Ariège-Pyrénées, Ariège, France, LXV-LXVI, 2010-2011; pp. 377-388.

147. Strecker, M. Hand Images in Mayan Caves. International Federation of Rock Art Organizations 2013 Proceedings, American Indian Rock Art; ARARA: Glendale, AZ, USA, 2013; Volume 40, pp. 507-528.

148. Keyser, J.D.; Dobrez, L.A.C.; Hann, D.; Kaiser, D.A. How is a picture a narrative? Interpreting different types of rock art. Am. Indian Rock Art 2013, 39, 83-99.

149. Merleau-Ponty, M. Phenomenology of Perception; Routledge \& Kegan Paul: London, UK, 1962; translated by C. Smith.

150. Reed, C.; Stone, V.E. Turning configural processing upside down: Part and whole body postures. J. Exp. Psychol.: Hum. Percept. Perform. 2006, 32, 73-87.

151. Walsh, G.L. Australia's Greatest Rock Art; E. J. Brill/Robert Brown \& Associates: Bathurst, Australia, 1988. 
152. Bednarik, R.G. The Origins of Human Behavior. In Pyschology of Human Behavior; Bednarik, R.G., Ed.; Psychology of Emotions, Motivations and Actions series; Nova Science Publications: New York, NY, USA, 2013; pp. 1-58.

(C) 2013 by the author; licensee MDPI, Basel, Switzerland. This article is an open access article distributed under the terms and conditions of the Creative Commons Attribution license (http://creativecommons.org/licenses/by/3.0/). 